\title{
A numerical study of internal brick stresses in AGR moderator bricks
}

DOI:

10.1016/j.nucengdes.2016.09.007

\section{Document Version}

Accepted author manuscript

Link to publication record in Manchester Research Explorer

\section{Citation for published version (APA):}

McNally, K., Fahad, M., Tan, E., Warren, N., Hall, G. N., \& Marsden, B. J. (2016). A numerical study of internal brick stresses in AGR moderator bricks. Nuclear Engineering and Design, 309, 277-293.

https://doi.org/10.1016/j.nucengdes.2016.09.007

\section{Published in:}

Nuclear Engineering and Design

\section{Citing this paper}

Please note that where the full-text provided on Manchester Research Explorer is the Author Accepted Manuscript or Proof version this may differ from the final Published version. If citing, it is advised that you check and use the publisher's definitive version.

\section{General rights}

Copyright and moral rights for the publications made accessible in the Research Explorer are retained by the authors and/or other copyright owners and it is a condition of accessing publications that users recognise and abide by the legal requirements associated with these rights.

\section{Takedown policy}

If you believe that this document breaches copyright please refer to the University of Manchester's Takedown Procedures [http://man.ac.uk/04Y6Bo] or contact uml.scholarlycommunications@manchester.ac.uk providing relevant details, so we can investigate your claim.

\section{OPEN ACCESS}




\title{
A numerical study of internal brick stresses in AGR moderator bricks
}

\author{
K. McNally ${ }^{1 *}$, E. Tan ${ }^{1}$, N.Warren ${ }^{1}$ \\ M.Fahad', G.N. Hall'2, B.J. Marsden ${ }^{2}$ \\ ${ }^{1}$ Health and Safety Laboratory, Harpur Hill, Buxton, Derbyshire, SK17 9JN, UK \\ ${ }^{2}$ NGRG, School of MACE, University of Manchester, Manchester, M13 9PL, UK \\ *Corresponding author \\ (C) Crown Copyright 2016
}

\begin{abstract}
Physically-based models are often used to model changes in geometry and the associated stress fields of graphite moderator bricks within an advanced gas-cooled reactor (AGR). These models require inputs that describe the loading conditions, and coded relationships describing the behaviour of material properties. Material relationships are primarily based upon data obtained from inspection campaigns at operating reactors. However, the data from trepanning campaigns do not provide information on some of the key relationships and parameters that affect the internal stresses generated within the moderator bricks. In this work we explore how uncertain material property relationships affect the internal brick stresses in early- and late-life. We describe two computer experiments designed to study early- and late-life brick stresses and report the results from global sensitivity analysis of the models. The work makes use of an emulator, a surrogate for the FE model, in order to make the sensitivity analyses computationally feasible.
\end{abstract}

\section{Keywords}

Global sensitivity analysis, stress analysis, finite element, AGR

\section{Introduction}

The advanced gas-cooled reactor (AGR) is a second-generation nuclear reactor that is unique to the UK. The AGR uses graphite as the neutron moderator and carbon dioxide gas as the coolant. The graphite also plays an important structural role providing channels for the fuel stringers and ensuring that fuel is adequately cooled under all normal operating and fault conditions. The graphite moderator also forms interstitial channels to provide access for control rods for controlling the reactor (Steer, 2006). The structural integrity of the graphite bricks, and the channels that they form, is of prime importance to AGR safety. The need to ensure safe shut down and fuel cooling is the essential safety requirement of any nuclear reactor.

Over the lifetime of the AGR there is a significant degradation of the graphite. In a carbon dioxide-cooled AGR it is known that the dimensional and properties changes of the graphite are not only a function of fast neutron damage and temperature but are also modified by radiolytic oxidation, which is quantified as a loss-of-mass or weight loss compared with the start-of-life condition (Brocklehurst et al., 1990). Information on property changes from Materials Test reactor (MTR) programmes and core monitoring is therefore important for 
quantifying changes in the moderator. The graphite core is a fairly inaccessible structure, although visual inspection of the fuel channel wall, dimensional measurement of the channel bore, and the removal of small samples of irradiated graphite so that material properties may be determined, are possible when the reactor is shutdown or is being refulled.

Core monitoring is supplemented by computer models of graphite components, resolved using the finite element method (Tsang and Marsden, 2006; Jones, 2006). Computer models are required in order to study the internal brick stresses that evolve due to changes to material properties of the graphite and the loading conditions in reactor. As input these models take through life loading conditions quantified by field variables for weight loss, fluence and temperature and materials property models that quantify changes to the microstructure of the graphite. A highly multivariate output of spatially and longitudinally varying displacements, strains and stresses is produced as model output.

However, computer models failed to (and still fail to) predict early life cracking (observed during core inspection) in a subset of moderator bricks, which indicates an imprecision in some model input. Whilst early life 'bore-initiated' cracks have not caused a safety concern, more extensive cracking is anticipated to occur from the keyway root of the moderator brick in late life (after shrinkage-induced stress reversal) and is considered a potentially life limiting fault for the graphite core. Due to imprecisely known relationships for some properties and to variability in the loading conditions between bricks, there is considerable uncertainty in both the timing of the onset and subsequent rate of propagation of keyway root initiated cracking. A significant programme of work by the licensee aims to reduces these uncertainties (eds Flewitt and Wickham, 2015).

Historically material properties relationships were based upon data obtained from materials test reactor (MTR) programmes. However, data obtained from trepanning campaigns at operating AGRs have provided longitudinal datasets for improving some material property relationships. Empirical models that quantify the effects of irradiation damage on Young's modulus (Eason et al., 2013a), bending strength (Eason et al., 2013b) and the coefficient of thermal expansion (CTE) (Eason et al., 2013c), which are consistent with data from MTR and AGR environments, have recently been published. McNally et al. (2014) developed a novel approach for improving the irradiation-induced (with grain) dimensional change material relationship that involved tuning model parameters such that predictions of displacements from the computer model were consistent with measured displacements in fuel channels.

Irradiation creep is a key property where MTR data are weakly informative of the AGR operating environment and whilst work to relate the ovalisation of moderator bricks to irradiation creep is a promising area of research, the operating AGRs themselves are yet to provided useable information with which to improve the coded material relationship for irradiation creep. This coded relationship is therefore both highly uncertain, and considered to be an important factor in internal brick stresses (Tsang and Marsden, 2008). In this work we explore the impact of uncertainty in the parameters of the irradiation creep coded relationship using two computer experiments to study stresses at the bore in early life, and at the keyway root in late life respectively.

Deterministic computer models (simulators) have been studied since the late 1980s in computer experiments. A computer experiment describes the process of defining plausible ranges for uncertain model parameters and subsequently running the simulator at different parameter (input) configurations in order to understand the behaviour of the outputs from the computer model. Efficient designs, such as a Latin Hypercube Design (LHD), are available 
for studying highly parameterised models with a relatively modest number of runs. A good overview on the design and analysis of computer experiments can be found in Santner et al. (2003).

The concept of developing a surrogate model, or emulator, for the simulator based upon data from a computer experiment was first proposed by Sacks et al. (1989). The original purpose of an emulator was as a fast approximation to the computationally expensive simulator. However, a range of applications have been developed in the past decade. A nontechnical overview of various applications where emulators have been utilised, collectively referred to as the Bayesian Analysis of Computer Code Outputs (BACCO) is given in O'Hagan (2006); the references therein provide technical detail. The two specific applications of interest in the currently work are uncertainty analysis (UA) and Global Sensitivity Analysis (GSA), which are the study of the uncertainty in model outputs that results from uncertainty in the inputs, and the study of which input(s) are the principle contributors in driving the uncertainty, respectively. UA and GSA based upon an emulator can be carried out using a small fraction of the many thousands of runs required using traditional Monte Carlo sampling applied directly to the simulator.

The remainder of the paper is set-out as follows. In methods firstly we provide brief details about the modelled components and an overview of the FE modelling approach used in this work, before describing the specific objectives, preliminary investigations, the models and the chosen outputs in two computer experiments. Finally some technical details on the emulator and the UA and GSA techniques are given. We describe the results from these experiments and comment on the information gained about the stresses and the uncertain material relationships. Finally we comment on work in progress.

\section{Methods}

\subsection{The Finite Element modelling approach}

The moderator bricks chosen for the experiments were those from the central core region of Hinkley Point B (HPB). Due to symmetry in the geometry (Figure 1 (a)) and the loading of the brick, only an octant $\left(45^{\circ}\right.$ sector) of a brick with full axial height was modelled (Figure 1(b)). Furthermore, a simplified geometry that excluded some of the finer details (such as the brick end features) was modelled. This allowed a coarser FE mesh to be used, which substantially reduced the computational time. However, the region of interest including methane holes, loose and interstitial keyways (Figure 1(b)) were included in the FE mesh (Figure 1(c)). ABAQUS Standard 6.12-1 and 3D stress, 20 node, quadratic brick elements (C3D20R) with reduced integration were used for the graphite brick analyses.

In FE modelling of nuclear graphite moderator bricks the temporal and spatial distributions of loads are used in the form of field variables which describes the distribution of fast neutron fluence, irradiation temperature and weight loss (Fahad et al., 2013; McNally et al., 2014). Field variables specific to Reactor 3 (R3), the fleet leading reactor, at two full power years increments (fpy), were used in this work. Examples of the spatial distribution of field variables are shown for a layer four moderator brick in Figure 2.

In order to model the effects of fast neutron irradiation and radiolytic oxidation on the graphite dimensional and material properties, a subroutine that includes the constitutive relationships is used with the finite element code. This type of subroutine is known as a user 
material or UMAT, and the one used in this study was coded at The University of Manchester and is called ManUMAT (Tsang, and Marsden, 2008). Subsets of the parameters in the UMAT were varied in each of the experiments (as described below).

\subsubsection{Experiment 1: Early-life (bore-initiated) cracking}

The objective of the first experiment was to investigate whether credible variations in the parameters related to irradiation creep could lead to a stress environment (i.e. stress exceeding the material strength) that was sufficient for early-life bore-initiated cracks to develop. The chosen output was the ratio of hoop stress to mean bending strength (Eason et al., 2013b) in a layer seven moderator brick. The ratio was chosen since both stress and strength vary spatially and since cracking is driven by the material resistance to stresses rather than high stresses alone.

Its is widely accepted that circular holes in a continuum can act as stress raisers, therefore in preliminary investigations stress to strength ratios at sub-surface adjacent to the first row of methane holes (Figure 1 ) in addition to at the bore were analysed with all model parameters set at baseline values. A comparison of this ratio (throughout the full height of the brick in each respective location) for three locations aligned with the loose keyway (at the bore, and at the near-bore and far-bore sides of the first methane hole) and at the equivalent three locations aligned with the interstitial keyway (as shown in Figure 3) was made (Figure 4). It was observed that during the time period of interest the ratio was greatest sub-surface (near bore) and aligned with the interstitial keyway. In the subsequent computer experiment the key output was maximum stress to strength ratio throughout the height of the brick at this location.

Twenty parameters were varied in the computer experiment. Baseline values and parameter variations are given in Table 1. A 100 point mini-max latin hypercube design (LHD) was generated and the FE model was run to $40 \mathrm{fpy}$ with simulated shutdowns at $2 \mathrm{fpy}$ intervals. Model output at power in $0.5 \mathrm{fpy}$ increments and at shutdown at $2 \mathrm{fpy}$ intervals (for 0 to 40 fpy) was obtained for each of these 100 model runs.

\subsubsection{Experiment 2: Keyway-root stresses}

The objective of the second experiment was to investigate how uncertainties in the parameters of material relationships, and variability in the loading conditions between moderator bricks (expressed in terms of a variability in the field variables), might influence later life stresses at the keyway root and hence influence the time of onset and the subsequent rate of keyway-root initiated cracking in the main population of bricks at $\mathrm{HPB}^{1}$. The maximum in-plane principle stress (MIPPS) at the keyway root was selected as the model output for investigation.

Some preliminary model runs were made in order to investigate the degree of mesh refinement around the keyway root that was required for accurate modelling of stresses, and to determine the difference in stresses at the loose and interstitial keyways. A greater refinement of the mesh around the keyways was seen to have an important influence, raising stresses by up to $5 \mathrm{MPa}$ at later life: the refined mesh was therefore used in all

\footnotetext{
${ }^{1}$ Two keyway root initiated cracks have been observed at Hunterston B Reactor 4 in 2014; however these have occurred in a small outlying high-shrinkage population of the moderator bricks.
} 
subsequent model runs. A comparison of MIPPS at the loose and interstitial keyways was made (Figure 5) and preliminary analysis showed that MIPPS was significantly greater at the interstitial keyway root throughout the time-period of interest. Therefore only the interstitial keyway was considered in subsequent computer experiment.

Thirty-six parameters were selected based upon conservative expert judgement and were varied in the computer experiment. Baseline values and parameter variations, are given in Table 2. A 200 point mini-max LHD was generated and model output at power and at shutdown at $2 \mathrm{fpy}$ intervals ( 0 to $40 \mathrm{fpy}$ ) was obtained for each of these 200 model runs.

\subsubsection{Structural uncertainties in FE models}

There are two classes of uncertain parameters in the FE models used in this work. Some parameters represent uncertain contants and the ranges used in the computer experiments are based upon experimental work. A larger pool of parameters represent uncertain parameters in material property models. The constants and material property parameters are identified in Tables 1 and 2 . For the constant parameters only parameter value uncertainty needs to be considered and this is achieved through the ranges on these parameters. For material property model parameters, both uncertainty in the material property model and parameter value uncertainty are relevant.

The majority of material property models coded in the ManUMAT are empirical models that were initially developed using pattern recognition techniques applied to a large database of material test reactor data for experiments conducted in inert environments, for multiple graphite grades and for various temperature ranges. The models for coefficient of thermal expansion (CTE) (Eason et al., 2013c), modulus (Eason et al., 2013a), and bending strength (Eason et al., 2013b) were subsequently modified to account for the oxidising environment of the AGR and some additional station specific parameters (accounting for differences in the reactor design and the operating environment between stations) were estimated using specimens removed from graphite bricks during trepanning campaigns. These empirical models are a good fit to MTR and AGR data. Through varing the parameters of these models all credible material property evolution is captured, therefore model uncertainty is considered to be negligible.

The model for creep used in these experiments was the UKAEA creep model (Kelly and Brocklehurst, 1977). The creep model also includes a modification to the CTE as a function of creep strain (Kelly, 1992; Preston and Marsden, 2006), and a relationship between dimensional change, creep strain and CTE. The creep model is subject to greater uncertainty since the data underpinning the model are only available from MTR experiments which achieved approximately one third of the fluence achieved by the AGRs under study. Creep is therefore subject to model uncertainty although this is difficult to quantify and this source of uncertainty is not explicitly included in current work. However, the parameter ranges for creep parameters are wide and thus significant material property variation is still achieved in the experiments. A revision to the creep model (Marsden et al., 2016) might be appropriate if MTR data at high fluence from ongoing creep experiments suggest a more complex model is appropriate.

As input the material property models take temperature, fluence and weight loss therefore it is necessary to provide these quantities in order to study the evolution of these material properties and the resulting generation of internal brick stresses. Temperature, fluence and weight loss are supplied as additional input to the FE model in the form of field variables 
with the triplet of temperature, fluence and weight loss supplied to the FE solver for each node and each time point (zero to 40 full power years in 2 full power year increments). Field variables are themselves calculated by models.

The graphite temperature data is calculated using a thermo-hydraulics code called PANTHER which accounts for coolant flow through the core and nuclear heating. The coolant temperatures are calculated throughout the core. The spatial graphite component temperatures are then calculated using these gas temperatures as boundary conditions.

Fluence is calculated by the reactor physics code MCBEND. As input this model takes 1) core and component geometry in particular fuel, moderator absorbers etc. 2) core and component elemental and isotopic constituents i.e. uranium, carbon, impurities, boron etc. 3) nuclear physic data from various international nuclear data sets.

Weight loss is calculated using the reactor physics code FEAT DIFFUSE. This code predicts the weight loss by solving spatially varying flow and gas concentration equations. The inputs to the code are 1) the virgin and irradiated graphite chemical properties such as oxidation rates as a function of coolant composition 2) AGR operating parameters, fluence, temperatures and gas composition and pressure.

Systematic variability in field variables is considered in current work, however uncertainties in the calculations used to derive the field variables are not considered in current work - for the weight loss calculations there are known issues with the FEAT DIFFUSE code which are being addressed in an ongoing review of the code (Wickham, 2016).

\subsection{Emulation of stresses}

The motivation behind the development of a surrogate model is computational efficiency. The solving and post-processing of the output for the FE models used in this work take approximately one hour of computational time for a single evaluation, with eight processors each having $4 \mathrm{~Gb}$ of memory. The higher computational time is due to finer mesh density . It is feasible to make several hundred evaluations but not the many thousands demanded by conventional uncertainty and sensitivity analysis techniques. An emulator built using data obtained from a well-designed computer experiment provides the necessary efficiency gains that are required for a computationally feasible UA and GSA to be performed.

The principal underlying assumption used to construct the emulator is that the output is a homogeneously smooth, continuous function of the input parameters. As a direct result of the underlying smoothness, the model output at inputs $\mathbf{x}$ conveys some information about the model output at some adjacent input configuration $\mathbf{x}^{*}$. A further implicit assumption of the method, for highly parameterized models, is the majority of variability in output is driven by a subset of the inputs. For example the 200 model evaluations in the second experiment would offer very sparse coverage of a 36-dimensional input parameter space if all the inputs had an important effect on the output. The inputs to the model fall into three categories: those with zero or a negligible effect on the output(s) of interest; inputs with a modest or simple (such as a linear) relationship with the model output; influential and potentially interacting inputs. An implicit assumption is that the latter group of inputs is a small subset of the uncertain varying parameters, although it is not necessary to be able to identify this subset a priori. The LHD is a particularly efficient design for computer experiments as the coverage properties mean that if the output is insensitive to a subset of the varying 
parameters, the design is projected onto a lower dimensional hyper-plane with no redundancy of model runs.

As in McNally et al. (2014), the emulator used in this work was based upon a Gaussian Process (GP) regression model. This is a form of surface fit with some specific properties that are desirable for approximating a deterministic model. The emulator smoothly interpolates the data observed in the computer experiment and uncertainty in predictions made away from design points is quantified by a probability distribution (t-distribution) with a location dependent standard deviation. A prediction from the emulator and a quantification of the prediction uncertainty is available in a fraction of a second compared with the several hours required to run the FE model for a single evaluation. The model fitted in this work was implemented using the Gaussian Emulation Machine (GEM) software (Kennedy, 2005). Some additional technical detail on the overall conceptual approach is provided in supplementary material however full mathematical details of the approach can be found in Oakley and O'Hagan (2004).

For both of the computer experiments reported on, the fit of the emulator was assessed using cross-validation, one of a variety of techniques discussed in Bastos and O'Hagan (2008). The full set of model runs from the computer experiment are used to build the emulator and to estimate the parameters of the GP model before each of the design points are left out sequentially; the output is predicted using the remaining outputs and compared with the observed data. Again, more technical information is provided in supplementary material.

\subsubsection{Uncertainty and Sensitivity Analysis}

Uncertainty analysis is the study of the uncertainty in model outputs that results from uncertainty in the inputs. The mean and variance of the output provide information on the central tendency of the model output and on the variation in model output that results from uncertainty in the model inputs. These summaries are calculated by taking integrals (with respect to the joint probability distribution of the model inputs), which, for common choices of probability distributions for model inputs (such as uniform and Gaussian), can be calculated analytically using the emulator. The range of outputs from the computer experiment provides a good indication on the lower and upper bounds of the model output: due to the space filling properties of the LHD the range of outputs observed in the computer experiment is a reasonable approximation to the full uncertainty in model output. However, Monte Carlo sampling based upon the emulator can provide more detailed charecterisation.

Probabilistic GSA is the study of which input(s) are the principal contributors in driving the variability in model output. Two measures have been used in this work. The first measure is the calculation of main effects and first order interactions. These show the underlying trends in model output resulting from the variation in one and two inputs respectively, by averaging over the other inputs. The second measure of sensitivity is a decomposition of the variance into main effect and interaction variances. Main effects and total effect variances (a measure of the total interactions an input is involved with) are provided.

The fitting of the GP model and the subsequent model validation and uncertainty and sensitivity analyses were performed using the Gaussian Emulation Machine (GEM) software. The specific assumptions made in GEM allow the integrals required for the uncertainty and sensitivity analysis measures (described above) to be performed analytically and hence very 
large efficiency savings are made compared with traditional sampling-based approaches Additional detail is provided in supplementary material.

\subsubsection{Interfacing models and analysis procedure}

The experimental designs used in this work were generated in GEM and output as text (tab delimited files) with each row of output denoting a design point and the columns the individual parameter values. A Matlab script was written to sequentially read the design points from the text file, modify the ManUMAT inputs accordingly, run the FE analysis in ABAQUS Standard 6.12-1, and then post-process the results to obtain the required stress metrics. The results for each design point FE analysis were then output to GEM. In the final step the emulators were fitted to the input and output data, and uncertainty and sensitivity analyses were performed using the software.

\section{Results}

\subsection{Experiment 1: Early-life (bore-initiated) cracking}

The time profiles for the ratio of hoop stress to mean tensile strength are shown for each of the $100 \mathrm{FE}$ model runs, at power and at shutdown conditions, in Figure 6. For each of the simulations the ratio is plotted until the stresses at the methane hole went into compression (after shrinkage-induced stress-reversal), which varied across the simulations runs.

Results show very large variations in the stress to (mean) strength ratio at the methane hole at both power and shutdown. There is considerable variability in both the absolute peak of the ratio, and the time when this was forecast to occur. Even without further analysis there is some value in the information presented in Figure 6 since some of the profiles are unlikely to be credible. Through an expert examination of the profiles a refinement of the input parameter space could therefore be achieved.

Some consistent behaviour was observed across each of the 100 model runs and therefore some conclusions, independent of the (uncertain) inputs, can be drawn. In each run the stress to strength ratio at the methane hole peaked earlier and at a higher value at shutdown than at power. In a similar fashion, stresses at the methane hole went into compression at an earlier time in the shutdown condition in all 100 simulations, typically by 2 to 4 fpy.

The sensitivity analysis focussed on the results data from $10 \mathrm{fpy}$ to $16 \mathrm{fpy}$ where the stress to strength ratio was most elevated. GP models were fitted to the output data at 10,12, 14 and $16 \mathrm{fpy}$ (power and shutdown). The results in detail focus on the results for $10 \mathrm{fpy}$, which were broadly representative of this period.

Prior to executing the sensitivity analysis the quality of fit of the emulators was assessed. Figure 7 shows results from cross validation exercise at $10 \mathrm{fpy}$. From Figure 7 it is clear that the results from the experiment and the model predictions lie on a one-to-one line with small errors, and no evidence of systematic departure. It was therefore concluded that a sensitivity analysis based upon the emulator was an excellent surrogate for a sensitivity analysis upon the FE model itself. 
Results from the variance based sensitivity analysis are shown in Table 3 - these are in terms of sensitivity indices which are the proportions of variance explained by the parameter alone (main effect) and in combination with other parameters (total). In addition, main effect plots for the six most important parameters are shown in Figure 8; these six parameters are highlighted in italics in Table 3.

Of the 20 varying parameters in the computer model, 14 had a negligible impact on the stress to mean strength ratio at the methane hole. This result does not imply these parameters have no importance in the model, rather it implies that the variability in these parameters within the perturbed ranges used in the computer experiment have a negligible impact on the chosen model output and within the chosen time-frame. An important finding of this work was that the uncertainty in the parameters associated with primary creep had negligible influence. The variability seen in the simulations (Figure 6) was driven by six parameters associated with secondary creep. The main effect variances of these six parameters accounted for approximately $90 \%$ of the output variance with interactions between the parameters being generally small. The parameter 'Secondary creep Young's modulus weight loss fitting constant $k_{i}{ }^{\prime}$ was the most interacting (Table 3 ). This parameter accounts, in part, for the effect of radiolytic oxidation on irradiation-induced secondary creep using a modified or creep Young's modulus through (1) (Tsang and Marsden, 2006; Eason et al. 2013a).

$$
\frac{E_{\text {creep }}}{E_{\text {creep }}^{0}}=\left\{1+A\left(\frac{\vartheta}{B}\right)^{C-1} \exp \left[-\left(\frac{\vartheta}{B}\right)^{C}\right]\right\} \exp \left[-F \omega^{k}\right] f_{0}
$$

where $\vartheta$ is dose ratio, $\omega$ is weight loss (\%), $f_{0}$ is the ratio of static to dynamic Young's modulus and $A, B$ and $C$ are amplitude function, location function and shape function of irradiation temperature, respectively.

The main effect plots shown in Figure 8 show the average effect each that these six important parameters had on the stress to mean strength ratio at $10 \mathrm{fpy}$ (power and shutdown). For four parameters ('Secondary creep Poisson's ratio', 'Secondary creep Young's modulus weight loss fitting constant $\mathrm{k}_{\mathrm{i}}$ ', 'Secondary creep Unirradiated dynamic Young's modulus (WG)' and 'Secondary creep Unirradiated static to dynamic Young's modulus ratio') the stress to strength ratio increased as the input parameters were increased. The ratio decreased as the 'Secondary creep coefficient' and 'Secondary creep Young's modulus weight loss fitting constant $F_{i}$ ' were increased. The results were very similar for at power and shutdown conditions. The precise results from the sensitivity analysis did exhibit a time dependency and both the main effects and the associated sensitivity indices changed over time - in particular the relationship between the results from shutdown and at power conditions was not always as strong as that shown at $10 \mathrm{fpy}$, however the same subset of the parameters still accounted for the majority of output variability.

The maximum ratio of hoop stress to mean tensile strength that was observed in the experiment was 0.812 . The sensitivity analysis based on the emulator suggests that a ratio of approximately 0.9 might be achieved within the input ranges defined in the study, however this has not been verified by additional FE model runs. It is important to note that the metric used in this work was the ratio of hoop stress to mean strength. However, there is considerable variability in strength at any given weight loss or (density) (Eason et al., 2013b). Models of irradiated strength based upon trepanned cores of graphite show that the variability in strength can be approximated by a log-normal distribution. Failures are likely to 
coincide with the lower tail of the strength distribution. Hence, a ratio of stress to mean strength of less than unity will be sufficient to lead to regions of the graphite adjacent to the methane hole (aligned with the interstitial keyway) where stress exceeds strength in some bricks, and which might lead to cracking. A rigorous analysis of stress and strength with the aim of calibrating some of the sensitive model parameters using information on cracking would require refinement of the strength model to account for size effects in extrapolating from the trepanned slice to the larger volume graphite in the moderator brick, and also account for the difference between the uni-axial load applied in the testing environment and the biaxial stress field in the reactor. In preliminary calculations that ignored these refinements (that would lead to lower strengths), we found that some simulations would be consistent with the observed rate of axial cracking observed in early to mid-life.

\subsection{Experiment 2: Late-life stresses at the keyway}

The time profiles for the maximum in-plane principal stress (MIPPS) at the keyway root are shown for each of the $200 \mathrm{FE}$ model runs in Figure 9, at power and shutdown. The profiles show that stresses at the keyway remain consistently low in early life, at around $1 \mathrm{MPa}$. After $14 \mathrm{fpy}$, the MIPPS at shutdown begins to increase, reaching a peak between 34 and 40 fpy depending on the model run; the time at which stresses begin to increase and the time at which the peak MIPPS occurs varies greatly between model runs. At power, the stresses remain low up to around 21 to $26 \mathrm{fpy}$ when they start to increase, i.e. the stresses lag at power by over $7 \mathrm{fpy}$. By $40 \mathrm{fpy}$, there is considerable variation in the stresses between model runs, taking values between $3 \mathrm{MPa}$ and $110 \mathrm{MPa}$.

For each model run, MIPPS at shutdown is consistently greater than stresses at power prior to approximately $30 \mathrm{fpy}$. Thereafter, MIPPS at power approaches and eventually, for some runs, exceeds MIPPS at shutdown condition.

The sensitivity analysis focused on the results during late-life where the stresses at the keyway were elevated and model outputs diverged between the different model runs. Therefore GP models were fitted to the output data between 20 and $40 \mathrm{fpy}$ for the shutdown condition and 26 to $40 \mathrm{fpy}$ for the at power condition. As was carried out for Experiment 1, the quality of fit of the emulators was assessed prior to executing the sensitivity analysis. Figure 10 shows results from the cross validation exercise between 26 fpy and $40 \mathrm{fpy}$ where it can be seen that the outputs from the computer model and the model predictions for all time points lie very close to a one-to-one line with small errors, and no evidence of systematic departure. The absolute departures from the one-one line increase over time as can be seen by the increasing spread of cross-validation errors in the top panels, nevertheless the departures remain relatively small. It was therefore concluded that a sensitivity analysis based on the emulator was a good surrogate for a sensitivity analysis based upon the computer model itself.

Results from the variance based sensitivity analysis are shown in Tables 4 and 5 for power ( 26 to $40 \mathrm{fpy}$ ) and shutdown ( 20 to $34 \mathrm{fpy}$ ) conditions respectively - the time ranges for sensitivity analysis were based upon a comparison of stress profiles from the 200 runs (Figure 9). Only the eleven most influential parameters are presented in tables in each case. The remaining parameters each accounted for no more than $0.5 \%$ of the total variation at any time point. In addition main effect plots for the two field variable parameters (dose and weight loss) and the six most important graphite material property parameters are shown in 
Figures 11 and 12 for power and shutdown conditions respectively. Main effects are shown at three time points so that the changes in sensitivities can be visualised.

At power, seven parameters drove the variability seen between the model runs. 'Dose' was the most influential parameter in earlier life, explaining over $70 \%$ of the variability at $26 \mathrm{fpy}$. The output variance rapidly increased after 26 fpy (Figure 9 and Table 4) and uncertain graphite material property parameters in the computer model rather than the field variables dominated the variability in the predicted stresses. The proportion of the variation explained by 'Secondary creep YM fitting constant $F_{i}^{\prime}$ and 'Secondary creep YM fitting constant $k_{i}^{\text {' }}$ increases from near zero such that by $32 \mathrm{fpy}$, they exceed the variation explained by 'Dose'. For four parameters ('Dose', 'Secondary creep DYM ratio', 'Secondary creep YM fitting constant $k_{i}^{\prime}$ and 'YM weight loss fitting constant $k_{i}^{\prime}$ ) the MIPPS increased as the parameters were increased. The MIPPS decreased as 'Secondary creep coefficient' and 'Secondary creep YM fitting constant $F_{i}^{\prime}$ were increased (Figure 11). Although variability in dose had a greater impact upon MIPPS at greater burn-up (Figure 11) it accounted for a smaller proportion of variance which was dominated by uncertainty in graphite material property relationships in the computer model (Table 4). Uncertainty in weight loss had a much smaller effect on MIPPS at all-time points. However, weight loss is likely to have a considerably stronger effect on the probability of cracking through its correlation with strength.

The majority of parameters had little influence on stresses at shutdown. Variability in the simulations was driven by the dose field variable and four parameters related to the CTE and Young's Modulus relationships. These five parameters accounted for over $85 \%$ of variance at every time point. The CTE fitting parameter C2 was consistently the most influential throughout, explaining between 35 and $40 \%$ of the total variation. The influence of the CTE fitting parameter $C 1$ and Young's modulus (YM) fitting constants $F_{i}$ and $k_{i}$ increased with time. As with results for at power, the dose field variable had a larger impact upon MIPPS at greater burn-up (Figure 12) however it accounted for a smaller proportion of variance which was dominated by uncertainty in graphite material property relationships in the computer model (Table 5). Uncertainty in weight loss had only a small effect on MIPPS at all-time points (Figure 12). The two Young's Modulus fitting constants displayed the greatest interactions with other parameters. The main effect plots shown in Figure 12 show the average effect on MIPPS from the dose and weight loss field variables and the six most important uncertain material relationship parameters at 20,30 and 40 fpy. For four parameters ('CTE fitting parameter C2', 'Dose', 'Secondary creep YM fitting constant $k_{i}^{\text {' and }}$ 'YM weight loss fitting constant $k_{i}^{\prime}$ ) the MIPPS increased as the parameters were increased. The MIPPS decreased as 'CTE C1', 'SC YM $F_{i}^{\prime}$ and 'YM WL fitting $F_{i}^{\prime}$ were increased.

The empirical model for CTE is described in (Eason et al., 2013c). It is evident from (2) that the two fitting parameters $C 1$ and $C 2$ are the most influential in controlling CTE and it is believed that variation in the CTE effects the thermal stresses and hence the overall stress state.

$$
\alpha_{(20-120)}=A . B . f\left(T_{i r r}\right)\left[C_{1}-C_{2} \tanh \left(\frac{\vartheta-C_{3}}{C_{4} \vartheta+C_{5}}\right)\right]
$$

where, $\vartheta$ is dose ratio, irr $T$ is irradiation temperature, $A, B, C_{1}, C_{2}, C_{3}, C_{4}$ and $C_{5}$ are fitting parameters.

Unlike the results of Experiment 1 where similarities were seen between at-power and atshutdown conditions, the most influential parameters differed between power and 
shutdown conditions in Experiment 2. In addition, different subsets of the parameters accounted for the majority of variability at different time points. However, at both power

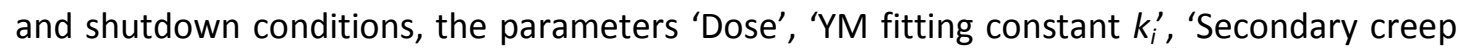
YM fitting constant $F_{i}^{\prime}$ and 'Secondary creep YM fitting constant $k_{i}^{\prime}$ were found to be amongst the most influential parameters. The precise results from sensitivity analysis did exhibit a time dependency and both the main effects and the associated sensitivity indices changed over time.

\section{Discussion}

In this work we ran two computer experiments to investigate how uncertainties associated with parameters in the ManUMAT impacted upon early and late-life stresses. In the first experiment we investigated a hypothesis that 'bore-initiated' axial cracks could potentially have initiated sub-surface at a methane hole aligned with the interstitial keyway. In the second experiment we quantified the uncertainty in MIPPS resulting from parameter variations. In both experiments the sensitivity analysis is a pre-curser to more ambitious research objectives - the use of data observed in-reactor to tune/calibrate and reduce the uncertainty in the parameters of the computer model. A similar modelling process was conducted, although not reported on in detail, prior to the calibration of the dimensional change parameters in McNally et al. (2014). The use of UA and GSA in this manner is consistent with good modelling practice. Rather than serving as an endpoint the correct application of these techniques is integral to the modelling process (French, 2003); it allows the prioritisation of resources and better focussing of subsequent research.

In the first experiment, whilst our main results concerned the stress to strength ratio at the methane hole aligned with the interstitial keyway, in preliminary research we investigated early life stresses at the bore and sub-surface at methane holes aligned with the loose and interstitial keyways. Our results suggest that the methane hole acts as a stress raiser; we believe that sub-surface stresses exceeding the strength of the graphite are a credible explanation for the observations of cracking seen in inspections of the bore. Considerable further work is required to bring this work to a conclusion. We noted in the results that analysis on the strength of irradiated graphite is required so that the relationship between weight loss and the strength of trepanned slices of graphite can be translated to the loading conditions of moderator bricks in-reactor. There is also the need to study (computationally) the propagation of a sub-surface crack in order to establish whether they might propagate through to the bore, to establish whether the simulated crack morphologies are consistent with observations, and to study how the crack growth might arrest (as seen in a substantial proportion of 'bore cracks' which extend to only a fraction of brick height or circumference).

Prediction of the observed cracking in early-life is an important outcome in its own right since it will provide enhanced confidence in the performance of the computer model. In addition, results from sensitivity analysis showed that four of the most influential parameters for determining the stress-to-strength ratio in the first experiment were also influential inputs in the second experiment. Therefore, by refining the parameter ranges based upon observations of early-life cracking, more robust estimates of the onset and rate of keyway root cracking might be achieved.

In the second experiment we varied two of the field variables considering $\pm 6 \%$ variability of dose around the baseline value and $\pm 4 \%$ variability in weight loss. These two field variables represent variability in loading conditions between bricks as opposed to uncertainty in 
material relationships - it is therefore an irreducible source of variability. Only variability in the dose field variable was found to be important, particularly so in the at-power condition. Whilst the dose field variable accounted for a smaller proportion of variance with increasing burn-up this was an artefact of variability resulting from other inputs to the model rapidly increasing over time rather than uncertainty resulting from variations in dose decreasing (Figures 9 and 11).

Whilst variation in dose accounted for a large proportion of output variability at-power up to $28 \mathrm{fpy}$, after this point the majority of variability in MIPPS resulted from uncertainty in the graphite material property relationships. For results at shutdown uncertain material relationships accounted for over $80 \%$ of output variability at all time-points. These sources of variability are reducible - more precise information on material relationships could potentially result in a very large decrease in output uncertainty. The parameter ranges used in this experiment were deliberately chosen to be wide to ensure that credible variations in each uncertain parameter were considered. The results from GSA have allowed a very substantial reduction in the number of 'candidate parameters' to be considered in further research since only seven of the 34 uncertain graphite material property parameters had a significant impact upon the model outputs of interest within the simulation range. These insensitive parameters can be considered fixed at central values in further work. Work is also ongoing to refine the ranges for the sensitive parameters: the results from UA (Figure 9) demonstrated that some of the parameter combinations led to very large stress predictions that were not physically credible. The GSA results allowed the parameter combinations associated with these non-credible stress predictions to be established. In current research the ranges for some of the sensitive parameters are being refined based upon an update to the empirical models for CTE (Eason et al., 2013c) and Young's modulus (Eason et al., 2013a) in the ManUMAT, and substantial reductions in the ranges for these parameters are anticipated. Whilst some of the predicted stresses do not appear physically credible we emphasise these are not wasted runs in our approach. These still provide important information for building the emulator and the information obtained will enable more precise interpolation within the region of credible input space. Once this process of refinement has been completed a simulation model will be developed for the comparison of MIPPS with strength at the keyway (modelled via a lognormal probability distribution for strength), in order to predict the likely onset and subsequent rate of keyway root cracking.

In the two experiments we varied 20 and 36 parameters respectively requiring 100 and 200 runs of the respective computer models. As mentioned in section 2.3, the solving and postprocessing of these models was a non-trivial computational expense. Running the experiments is an up-front investment in computational resource and there is a requirement to maximise the information obtained from each run: the use of well-designed computer experiments is critical to this process.

The use of emulators resulted in a very large efficiency gain and in doing so it made the sensitivity analysis computationally feasible: the many thousands of model evaluations required by other sensitivity analysis methods would have made a sensitivity analysis infeasible. Based upon 100 and 200 runs respectively we were able to screen out a large proportion of insensitive parameters (with respect to the outputs under study) and to determine how the subset of most sensitive parameters affected the model outputs under study, in both at-power and at-shutdown conditions. We were also able to study temporal variation in results. The knowledge gained from the sensitivity analyses reported in this work would justify the computational expense of the experiments. However, the data obtained from these experiments will also be sufficient for us to achieve the end objectives described 
for each experiment, to refine our knowledge of model parameters using observations of bore-cracking, and to simulate the onset and rate of keyway root cracking respectively. We have described above how we are currently refining the uncertainties associated with some model inputs - these refinements will not impact upon the way the model output responds to the inputs but by refining the inputs we will refine the range of model outputs that are consistent with uncertainty in the inputs. No additional runs of the computer model will be required. Similarly, the subsequent simulations of the core that will be made in further work such as a calibration exercise similar to that described in McNally et al. (2014), will be based upon the emulator. No further runs of the computer model are required (although additional validation runs may be made). Finally we note that whilst we have extracted specific outputs for study in this work the full set of model runs have been saved and can be interrogated to extract additional outputs as required. By considering such a wide range of parameters, even though only a fraction were found to be sensitive for the stress metrics used in this work, we have ensured that the breadth of data obtained in the experiments has potentially much wider use.

\section{Conclusions}

Computer models are required in order to study the internal brick stresses in AGR moderator bricks that evolve through-life due to changes to material properties of the graphite and the loading conditions in reactor. Whilst relatively large datasets are available (from operating AGR's) that allow empirical relationships to be estimated for some material properties, there is limited data on other important properties such as irradiation creep. Due to imprecisely known relationships for some material properties and to variability in the loading conditions between bricks there is significant uncertainty in the internal brick stresses.

The computer experiments documented in this work demonstrated that uncertainty in primary creep had a negligible effect on the uncertainty in brick stresses in early- and latelife. A similar small subset of parameters related to secondary creep was found to drive uncertainty in early- and late-life stresses. It was also demonstrated that uncertainty in loading conditions (primarily in dose) influenced the timing of stress reversal and hence when tensile stresses at the keyway develop, however uncertainty in material properties parameters was more important in driving uncertainty in MIPPS.

\section{Acknowledgments}

The authors would like to thank EdF Energy for providing the field variables for the FE models. This publication and the work it describes were funded by the Office of Nuclear Regulation (ONR). Its contents, including any opinions and/or conclusions expressed, are those of the authors alone and do not necessarily reflect HSE or ONR policy.

\section{References}

Bastos, L. S., and O'Hagan, A. (2008). Diagnostics for Gaussian Process Emulators. Technometrics, 51:4, 425-438. 
Brocklehurst, J.E., Brown, R.G., Gilchrist, K.E. and Labaton, V.Y. (1990), The Effect of Radiolytic Oxidation on the Physical Properties of Graphite, Journal of Nuclear materials 35, 183-194.

Eason, E. D., Hall, G. N., Marsden, B. J., and Heys, G. B. (2013a). A Model of Young's Modulus for Gilsocarbon Graphites Irradiated in Oxidising Environments. Journal of Nuclear Materials, 436, 201-207.

Eason, E. D., Hall, G. N., Marsden, B. J., and Heys, G. B. (2013b). Models of Bending Strength for Gilsocarbon Graphites Irradiated in Inert and Oxidising Environments. Journal of Nuclear Materials, 436, 208-216.

Eason, E. D., Hall, G. N., Marsden, B. J., and Heys, G. B. (2013c). Models of Coefficient of Thermal Expansion (CTE) for Gilsocarbon Graphites Irradiated in Inert and Oxidising Environments. Journal of Nuclear Materials, 436, 191-200.

Fahad, M., Hall, G., McNally, K., Marsden, B.J., Mummery, P. and Warren, N. (2013). A Statistical and Finite Element Modelling Approach used in the Derivation of Moderator Graphite Behaviour, Transactions, SMiRT-22, San Francisco, California, USA - August 18-23.

French, S. (2003) Modelling, Making Inferences and Making Decisions: The Roles of Sensitivity Analysis. Sociedad de Estatistica e investigacion operative, 11: 2, 229-251

Flewitt, P.E.J. and Wickham, A.J. (eds) (2015). The $4^{\text {th }}$ EDF Energy nuclear graphite symposium: Engineering challenges associated with the life of graphite reactor cores Emas Publishing, Warrington.

Jones, C. (2006). Predicting the Stresses and Deformations of Irradiated Graphite Moderator Bricks. Management of Ageing Processes in Graphite Reactor Cores, G. Neighbour, ed., Oxford: Oxford University Press, 167-174.

Kelly, B.T. and Brocklehurst, J.E. (1977). UKAEA Reactor Group Studies of irradiation-Induced Creep in Graphite. Journal of Nuclear Materials, 65,79-85.

Kelly, B.T. (1992). Irradiation Creep in Graphite - Some New Considerations and Observations. Carbon 30, 379-383.

Kennedy, M.C. (2005). GEM-SA, version 1.1. software: Gaussian Emulation Machine for Sensitivity Analysis.

Marsden, B.J., Haverty, M., Bodel, W., Jones, A.N., Mummery, P.M. and Treifi, M. (2016). Dimensional Change, Irradiation Creep and Thermal/Mechanical Property Changes in Nuclear Graphite. International Materials Reviews, 61:3, 155-182

McNally, K., Hall, G., Tan, E., Marsden, B.J. and Warren, N. (2014). Calibration of Dimensional Change in Finite Element Models Using AGR Moderator Brick Measurements, Journal of Nuclear Materials, 451,179-188.

O'Hagan, A. (2006). Bayesian Analysis of Computer Code Outputs: a tutorial. Reliability Engineering and System Safety, 91, 1290-1300.

Oakley, J. E., and O'Hagan, A. (2004). Probabilistic Sensitivity Analysis of Complex Models: a Bayesian Approach. Journal of the Royal Statistical Society. Series B (Statistical Methodology), 66:3, 751-769.

Preston, S.D., Marsden, B.J. (2006). Changes in the Coefficient of Thermal Expansion in Stressed Gilsocarbon Graphite. Carbon 44, 1250-1257.

Sacks, J., Welch, W. J., Mitchell, T. J., and Wynn, H. P. (1989). Design and Analysis of Computer Experiments." Statistical Science, 4:4, 409-423.

Santner, T. J., Williams, B., and Notz, W. (2003). The Design and Analysis of Computer Experiments, New York: Springer-Verlag.

Steer, A. G. (2006). AGR Core Design, Operation and Safety Functions. Management of Ageing Processes in Graphite Reactor Core, G. B. Neighbour, ed., Cambridge: RSC Publishing, 142-149. 
Tsang, D. K. L., and Marsden, B. J. (2006). The Development of a Stress Analysis Code for Nuclear Graphite Components in Gas-cooled Reactors, Journal of Nuclear Materials 350, 208-220

Tsang, D. K. L., and Marsden, B. J. (2008). Constitutive Material Model for the Prediction of Stresses in Irradiated Anisotropic Graphite Components. Journal of Nuclear Materials, 381:1, 129-136.

Wickham, A. (2016). Revisiting AGR Graphite Weight-Loss Predictions: A First-Principles Review of the Basis and Application of the FEAT-DIFFUSE Code in Flewitt, P.E.J. and Wickham, A.J. (eds) the $5^{\text {th }}$ EDF Energy nuclear graphite symposium: Science and Engineering in Collaboration to Support Safe Operation of the Graphite Reactor Cores. Emas Publishing, Warrington 
Table 1: Varying parameter and limits for Experiment 1

\begin{tabular}{|c|c|c|c|c|}
\hline Parameter & Baseline & Minimum & Maximum & Parameter class \\
\hline Primary creep coefficient & 1.0 & 0.8 & 1.2 & Creep model \\
\hline Primary creep Poisson's ratio & 0.20 & 0.14 & 0.32 & Constant \\
\hline Primary creep Young's modulus weight loss fitting constant $F_{i}$ & 6.025 & 0.000 & 9.500 & Creep model \\
\hline Primary creep Young's modulus weight loss fitting constant $k_{i}$ & 1.198 & 0.780 & 2.500 & Creep model \\
\hline Primary creep Unirradiated dynamic Young's modulus (WG) & $9610 \mathrm{MN} / \mathrm{m}^{2}$ & $8620 \mathrm{MN} / \mathrm{m}^{2}$ & $11240 \mathrm{MN} / \mathrm{m}^{2}$ & Constant \\
\hline Primary creep Unirradiated dynamic Young's modulus (AG) & $9480 \mathrm{MN} / \mathrm{m}^{2}$ & $8140 \mathrm{MN} / \mathrm{m}^{2}$ & $11100 \mathrm{MN} / \mathrm{m}^{2}$ & Constant \\
\hline Primary creep Unirradiated static to dynamic Young's modulus ratio & 0.84 & 0.64 & 1.04 & Constant \\
\hline Primary creep Irradiated dynamic Young's modulus amplitude term $a$ & 14.0 & 12.5 & 15.5 & Creep model \\
\hline Primary creep Irradiated dynamic Young's modulus location term $b$ & 0.966 & 0.900 & 1.050 & Creep model \\
\hline Primary creep Unirradiated Shear modulus & $3950 \mathrm{MN} / \mathrm{m}^{2}$ & $3555 \mathrm{MN} / \mathrm{m}^{2}$ & $4621.50 \mathrm{MN} / \mathrm{m}^{2}$ & Constant \\
\hline Secondary creep coefficient & 0.23 & 0.184 & 0.276 & Creep model \\
\hline Secondary creep Poisson's ratio & 0.20 & 0.14 & 0.32 & Constant \\
\hline Secondary creep Young's modulus weight loss fitting constant $F_{i}$ & 6.025 & 0.000 & 9.500 & Creep model \\
\hline Secondary creep Young's modulus weight loss fitting constant $k_{i}$ & 1.198 & 0.780 & 2.500 & Creep model \\
\hline Secondary creep Unirradiated dynamic Young's modulus (WG) & $9610 \mathrm{MN} / \mathrm{m}^{2}$ & $8620 \mathrm{MN} / \mathrm{m}^{2}$ & $11240 \mathrm{MN} / \mathrm{m}^{2}$ & Constant \\
\hline Secondary creep Unirradiated dynamic Young's modulus (AG) & $9480 \mathrm{MN} / \mathrm{m}^{2}$ & $8140 \mathrm{MN} / \mathrm{m}^{2}$ & $11100 \mathrm{MN} / \mathrm{m}^{2}$ & Constant \\
\hline Secondary creep Unirradiated static to dynamic Young's modulus ratio & 0.84 & 0.64 & 1.04 & Constant \\
\hline Secondary creep Irradiated dynamic Young's modulus amplitude term $a$ & 14.0 & 12.5 & 15.5 & Creep model \\
\hline Secondary creep Irradiated dynamic Young's modulus location term $b$ & 0.966 & 0.900 & 1.050 & Creep model \\
\hline Secondary creep Unirradiated Shear modulus & $3950 \mathrm{MN} / \mathrm{m}^{2}$ & $3555 \mathrm{MN} / \mathrm{m}^{2}$ & $4621.5 \mathrm{MN} / \mathrm{m}^{2}$ & Constant \\
\hline
\end{tabular}


Table 2: Varying parameters and limits for Experiment 2

\begin{tabular}{|c|c|c|c|c|}
\hline Parameter & Baseline & Minimum & Maximum & Parameter class \\
\hline Dose (FV1) & - & $-6 \%$ & $6 \%$ & - \\
\hline Weight loss (FV2) & - & $-4 \%$ & $4 \%$ & - \\
\hline CTE fitting parameter $\mathrm{C} 1$ & 3.532 & 3 & 4 & CTE model \\
\hline CTE fitting parameter $C 2$ & 2.021 & 1.5 & 3 & CTE model \\
\hline Unirradiated CTE (WG) & 4.35 & 4 & 6 & Constant \\
\hline Unirradiated CTE (AG) & 4.35 & 4 & 6 & Constant \\
\hline First polynomial for $\mathrm{Bi}$ & $-2.66 \mathrm{E}-01$ & -0.293 & -0.23971 & CTE model \\
\hline Second polynomial for $\mathrm{Bi}$ & 4.04E-03 & 0.00363 & 0.00444 & CTE model \\
\hline Third polynomial for $\mathrm{Bi}$ & $1.67 \mathrm{E}-07$ & $1.5 \mathrm{E}-07$ & $1.84 \mathrm{E}-07$ & CTE model \\
\hline Fourth polynomial for $\mathrm{Bi}$ & $-3.38 \mathrm{E}-09$ & $-3 E-09$ & $-3.7 E-09$ & CTE model \\
\hline Fifth polynomial for $\mathrm{Bi}$ & $1.58 \mathrm{E}-12$ & $1.4 \mathrm{E}-12$ & $1.73 \mathrm{E}-12$ & CTE model \\
\hline Unirradiated Young's modulus (WG) & $9610 \mathrm{MN} / \mathrm{m}^{2}$ & $8620 \mathrm{MN} / \mathrm{m}^{2}$ & $11240 \mathrm{MN} / \mathrm{m}^{2}$ & Constant \\
\hline Unirradiated Young's modulus (AG) & $9480 \mathrm{MN} / \mathrm{m}^{2}$ & $8140 \mathrm{MN} / \mathrm{m}^{2}$ & $11100 \mathrm{MN} / \mathrm{m}^{2}$ & Constant \\
\hline Unirradiated Shear modulus & $3950 \mathrm{MN} / \mathrm{m}^{2}$ & $3555 \mathrm{MN} / \mathrm{m}^{2}$ & $4621 \mathrm{MN} / \mathrm{m}^{2}$ & Constant \\
\hline Irradiated static to dynamic Young's modulus & 0.92 & 0.9 & 0.98 & Constant \\
\hline Young's modulus pinning term $p$ & 1.76 & 1.45 & 2 & Modulus model \\
\hline Irradiated dynamic Young's modulus amplitude term $a$ & 14 & 12.5 & 15.5 & Modulus model \\
\hline Irradiated dynamic Young's modulus location term $b$ & 0.966 & 0.9 & 1.05 & Modulus model \\
\hline Young's modulus weight loss fitting constant $F_{i}$ & 6.025 & 0 & 9.5 & Modulus model \\
\hline Young's modulus weight loss fitting constant $k_{i}$ & 1.198 & 0.78 & 2.5 & Modulus model \\
\hline Poisson's ratio & 0.2 & 0.14 & 0.32 & Constant \\
\hline Unirradiated tensile strength & $18.85 \mathrm{MN} / \mathrm{m}^{2}$ & $16 \mathrm{MN} / \mathrm{m}^{2}$ & $21.6 \mathrm{MN} / \mathrm{m}^{2}$ & Constant \\
\hline Density based strength-fitting constant $\mathrm{Ci}$ & 4.679 & 3.679 & 5.679 & Strength model \\
\hline Density based strength-fitting constant $\mathrm{Ni}$ & 4.067 & 3.067 & 5.067 & Strength model \\
\hline Density based strength-fitting constant $m$ & 0.1582 & 0.1 & 0.2 & Strength model \\
\hline
\end{tabular}




\begin{tabular}{|c|c|c|c|c|}
\hline Secondary creep coefficient & 0.23 & 0.184 & 0.276 & Creep model \\
\hline Secondary creep Poisson's ratio & 0.20 & 0.14 & 0.32 & Constant \\
\hline Secondary creep Young's modulus weight loss fitting constant Fi & 6.025 & 0.000 & 9.500 & Creep model \\
\hline Secondary creep Young's modulus weight loss fitting constant ki & 1.198 & 0.780 & 2.500 & Creep model \\
\hline Secondary creep Unirradiated dynamic Young's modulus (WG) & $9610 \mathrm{MN} / \mathrm{m}^{2}$ & $8620 \mathrm{MN} / \mathrm{m}^{2}$ & $11240 \mathrm{MN} / \mathrm{m}^{2}$ & Constant \\
\hline Secondary creep Unirradiated dynamic Young's modulus (AG) & $9480 \mathrm{MN} / \mathrm{m}^{2}$ & $8140 \mathrm{MN} / \mathrm{m}^{2}$ & $11100 \mathrm{MN} / \mathrm{m}^{2}$ & Constant \\
\hline Secondary creep Unirradiated static to dynamic Young's modulus ratio & 0.84 & 0.64 & 1.04 & Constant \\
\hline Secondary creep Irradiated dynamic Young's modulus amplitude term $a$ & 14.0 & 12.5 & 15.5 & Creep model \\
\hline Secondary creep Irradiated dynamic Young's modulus location term $b$ & 0.966 & 0.900 & 1.050 & Creep model \\
\hline Secondary creep Unirradiated Shear modulus & $3950 \mathrm{MN} / \mathrm{m}^{2}$ & $3555 \mathrm{MN} / \mathrm{m}^{2}$ & $4621.5 \mathrm{MN} / \mathrm{m}^{2}$ & Constant \\
\hline
\end{tabular}


Table 3: Main and total effect sensitivity indices for the 20 input parameters in the experiment. Results are based on an analysis of outputs at $10 f p y$ for the at power and shutdown conditions.

\begin{tabular}{|c|c|c|c|c|}
\hline \multirow{2}{*}{ Parameter } & \multicolumn{2}{|c|}{ Power (10 fpy) } & \multicolumn{2}{|c|}{ Shutdown (10 fpy) } \\
\hline & Main effect & Total effect & Main effect & Total effect \\
\hline Primary creep coefficient & 0.0001 & 0.0005 & 0.0001 & 0.0005 \\
\hline Primary creep Poisson's ratio & 0.0000 & 0.0000 & 0.0000 & 0.0000 \\
\hline Primary creep Young's modulus weight loss fitting constant $F_{i}$ & 0.0019 & 0.0093 & 0.0018 & 0.0092 \\
\hline Primary creep Young's modulus weight loss fitting constant $k_{i}$ & 0.0057 & 0.0136 & 0.0058 & 0.0137 \\
\hline Primary creep Unirradiated dynamic Young's modulus (WG) & 0.0011 & 0.0016 & 0.0011 & 0.0016 \\
\hline Primary creep Unirradiated dynamic Young's modulus (AG) & 0.0000 & 0.0000 & 0.0000 & 0.0000 \\
\hline Primary creep Unirradiated static to dynamic Young's modulus ratio & 0.0002 & 0.0023 & 0.0002 & 0.0023 \\
\hline Primary creep Irradiated dynamic Young's modulus amplitude term $a$ & 0.0000 & 0.0000 & 0.0000 & 0.0000 \\
\hline Primary creep Irradiated dynamic Young's modulus location term $b$ & 0.0000 & 0.0001 & 0.0000 & 0.0000 \\
\hline Primary creep Unirradiated Shear modulus & 0.0000 & 0.0000 & 0.0000 & 0.0000 \\
\hline Secondary creep coefficient & 0.2310 & 0.2474 & 0.2319 & 0.2489 \\
\hline Secondary creep Poisson's ratio & 0.0535 & 0.0628 & 0.0537 & 0.0629 \\
\hline Secondary creep Young's modulus weight loss fitting constant $F_{i}$ & 0.0421 & 0.0857 & 0.0418 & 0.0852 \\
\hline Secondary creep Young's modulus weight loss fitting constant $k_{i}$ & 0.2094 & 0.2763 & 0.209 & 0.276 \\
\hline Secondary creep Unirradiated dynamic Young's modulus (WG) & 0.0739 & 0.0808 & 0.0735 & 0.0804 \\
\hline Secondary creep Unirradiated dynamic Young's modulus (AG) & 0.0000 & 0.0000 & 0.0000 & 0.0000 \\
\hline Secondary creep Unirradiated static to dynamic Young's modulus ratio & 0.2825 & 0.3011 & 0.2823 & 0.3009 \\
\hline Secondary creep Irradiated dynamic Young's modulus amplitude term $a$ & 0.0003 & 0.0017 & 0.0003 & 0.0017 \\
\hline Secondary creep Irradiated dynamic Young's modulus location term $b$ & 0.0056 & 0.0175 & 0.0056 & 0.0175 \\
\hline Secondary creep Unirradiated Shear modulus & 0.0008 & 0.0058 & 0.0008 & 0.0058 \\
\hline
\end{tabular}


Table 4: Main and total effect sensitivity indices (brackets) for the most influential input parameters in the experiment. Results are based on an analysis of outputs at between $26 \mathrm{fpy}$ and $40 \mathrm{fpy}$ for the at power condition.

\begin{tabular}{|c|c|c|c|c|c|c|c|c|}
\hline Parameter & $26 \mathrm{fpy}$ & $28 \mathrm{fpy}$ & $30 \mathrm{fpy}$ & $32 \mathrm{fpy}$ & $34 \mathrm{fpy}$ & $36 \mathrm{fpy}$ & $38 \mathrm{fpy}$ & $40 \mathrm{fpy}$ \\
\hline Dose (FV1) & \begin{tabular}{|c|}
0.729 \\
$(0.776)$ \\
\end{tabular} & \begin{tabular}{|c|}
0.499 \\
$(0.550)$ \\
\end{tabular} & $\begin{array}{c}0.326 \\
(0.360) \\
\end{array}$ & $\begin{array}{c}0.221 \\
(0.244) \\
\end{array}$ & $\begin{array}{c}0.154 \\
(0.173)\end{array}$ & $\begin{array}{c}0.109 \\
(0.124)\end{array}$ & $\begin{array}{c}0.080 \\
(0.093)\end{array}$ & $\begin{array}{c}0.060 \\
(0.069) \\
\end{array}$ \\
\hline Weight loss (FV2) & \begin{tabular}{|c|}
0.007 \\
$(0.008)$ \\
\end{tabular} & $\begin{array}{c}0.008 \\
(0.010) \\
\end{array}$ & $\begin{array}{c}0.006 \\
(0.007)\end{array}$ & $\begin{array}{c}0.005 \\
(0.005)\end{array}$ & $\begin{array}{c}0.005 \\
(0.006)\end{array}$ & $\begin{array}{c}0.005 \\
(0.005)\end{array}$ & $\begin{array}{c}0.005 \\
(0.006)\end{array}$ & $\begin{array}{c}0.004 \\
(0.005) \\
\end{array}$ \\
\hline Young's modulus weight loss fitting constant $F_{i}$ & $\begin{array}{c}0.017 \\
(0.045)\end{array}$ & $\begin{array}{c}0.018 \\
(0.046)\end{array}$ & $\begin{array}{c}0.016 \\
(0.040)\end{array}$ & $\begin{array}{c}0.016 \\
(0.035)\end{array}$ & $\begin{array}{c}0.015 \\
(0.033)\end{array}$ & $\begin{array}{c}0.014 \\
(0.032)\end{array}$ & $\begin{array}{c}0.014 \\
(0.033)\end{array}$ & $\begin{array}{c}0.017 \\
(0.028)\end{array}$ \\
\hline Young's modulus weight loss fitting constant $k_{i}$ & $\begin{array}{c}0.061 \\
(0.103)\end{array}$ & $\begin{array}{c}0.048 \\
(0.085) \\
\end{array}$ & $\begin{array}{c}0.039 \\
(0.069)\end{array}$ & $\begin{array}{c}0.034 \\
(0.059)\end{array}$ & $\begin{array}{c}0.026 \\
(0.047)\end{array}$ & $\begin{array}{c}0.023 \\
(0.043)\end{array}$ & $\begin{array}{c}0.019 \\
(0.038)\end{array}$ & $\begin{array}{c}0.019 \\
(0.030)\end{array}$ \\
\hline Secondary creep coefficient & $\begin{array}{c}0.001 \\
(0.005) \\
\end{array}$ & $\begin{array}{c}0.008 \\
(0.013)\end{array}$ & $\begin{array}{c}0.023 \\
(0.027)\end{array}$ & $\begin{array}{c}0.032 \\
(0.035)\end{array}$ & $\begin{array}{c}0.038 \\
(0.042)\end{array}$ & $\begin{array}{c}0.041 \\
(0.044)\end{array}$ & $\begin{array}{c}0.041 \\
(0.045)\end{array}$ & $\begin{array}{c}0.040 \\
(0.043) \\
\end{array}$ \\
\hline Secondary creep_Young's modulus weight loss fitting constant $F_{i}$ & $\begin{array}{c}0.031 \\
(0.085) \\
\end{array}$ & $\begin{array}{c}0.109 \\
(0.184) \\
\end{array}$ & $\begin{array}{c}0.172 \\
(0.259)\end{array}$ & $\begin{array}{c}0.222 \\
(0.308)\end{array}$ & $\begin{array}{c}0.259 \\
(0.346)\end{array}$ & $\begin{array}{c}0.295 \\
(0.379)\end{array}$ & $\begin{array}{c}0.327 \\
(0.410)\end{array}$ & \begin{tabular}{|c|}
0.370 \\
$(0.440)$ \\
\end{tabular} \\
\hline Secondary creep_Young's modulus weight loss fitting constant $k_{i}$ & \begin{tabular}{|c|}
0.037 \\
$(0.097)$ \\
\end{tabular} & $\begin{array}{c}0.148 \\
(0.234) \\
\end{array}$ & $\begin{array}{c}0.235 \\
(0.327)\end{array}$ & $\begin{array}{c}0.285 \\
(0.373)\end{array}$ & $\begin{array}{c}0.313 \\
(0.401)\end{array}$ & $\begin{array}{c}0.328 \\
(0.413)\end{array}$ & $\begin{array}{c}0.333 \\
(0.416)\end{array}$ & $\begin{array}{c}0.335 \\
(0.400) \\
\end{array}$ \\
\hline Secondary creep_Unirradiated dynamic Young's modulus (WG) & $\begin{array}{c}0.001 \\
(0.004)\end{array}$ & $\begin{array}{c}0.001 \\
(0.004)\end{array}$ & $\begin{array}{c}0.003 \\
(0.004)\end{array}$ & $\begin{array}{c}0.005 \\
(0.005)\end{array}$ & $\begin{array}{c}0.006 \\
(0.007)\end{array}$ & $\begin{array}{c}0.007 \\
(0.008)\end{array}$ & $\begin{array}{c}0.007 \\
(0.008)\end{array}$ & $\begin{array}{c}0.005 \\
(0.006)\end{array}$ \\
\hline Secondary creep_Unirradiated static to dynamic Young's modulus ratio & $\begin{array}{c}0.000 \\
(0.000)\end{array}$ & $\begin{array}{c}0.016 \\
(0.027)\end{array}$ & $\begin{array}{c}0.038 \\
(0.044)\end{array}$ & $\begin{array}{c}0.051 \\
(0.056)\end{array}$ & $\begin{array}{c}0.056 \\
(0.061)\end{array}$ & $\begin{array}{c}0.057 \\
(0.063)\end{array}$ & $\begin{array}{c}0.055 \\
(0.061)\end{array}$ & $\begin{array}{c}0.058 \\
(0.064)\end{array}$ \\
\hline Secondary creep_Irradiated dynamic Young's modulus amplitude term a & $\begin{array}{c}0.000 \\
(0.000)\end{array}$ & $\begin{array}{c}0.002 \\
(0.003)\end{array}$ & $\begin{array}{c}0.003 \\
(0.003)\end{array}$ & $\begin{array}{c}0.003 \\
(0.003)\end{array}$ & $\begin{array}{c}0.003 \\
(0.004)\end{array}$ & $\begin{array}{c}0.003 \\
(0.004)\end{array}$ & $\begin{array}{c}0.004 \\
(0.004)\end{array}$ & $\begin{array}{c}0.003 \\
(0.003)\end{array}$ \\
\hline Secondary creep_Irradiated dynamic Young's modulus location term b & \begin{tabular}{|c|}
0.001 \\
$(0.001)$
\end{tabular} & $\begin{array}{c}0.002 \\
(0.002) \\
\end{array}$ & $\begin{array}{c}0.003 \\
(0.004)\end{array}$ & $\begin{array}{c}0.004 \\
(0.004)\end{array}$ & $\begin{array}{c}0.004 \\
(0.004)\end{array}$ & $\begin{array}{c}0.003 \\
(0.003)\end{array}$ & $\begin{array}{c}0.002 \\
(0.003)\end{array}$ & \begin{tabular}{|c|}
0.002 \\
$(0.002)$ \\
\end{tabular} \\
\hline Sum of main effects & 0.885 & 0.859 & 0.864 & 0.876 & 0.879 & 0.885 & 0.888 & 0.912 \\
\hline Total Variance & 10.9 & 26.11 & 53.8 & 97.9 & 164.1 & 247.6 & 348.6 & 451.2 \\
\hline
\end{tabular}


Table 5: Main and total effect sensitivity indices (brackets) for the most influential input parameters in the experiment. Results are based on an analysis of outputs at 20 to $34 \mathrm{fpy}$ for the at shutdown condition.

\begin{tabular}{|c|c|c|c|c|c|c|c|c|}
\hline Parameter & $20 \mathrm{fpy}$ & 22 fpy & $24 \mathrm{fpy}$ & $26 \mathrm{fpy}$ & $28 \mathrm{fpy}$ & $30 \mathrm{fpy}$ & $32 \mathrm{fpy}$ & 34 fpy \\
\hline Dose (FV1) & \begin{tabular}{|c|}
0.154 \\
$(0.181)$ \\
\end{tabular} & \begin{tabular}{|c|}
0.163 \\
$(0.174)$ \\
\end{tabular} & $\begin{array}{c}0.145 \\
(0.152) \\
\end{array}$ & $\begin{array}{c}0.122 \\
(0.126) \\
\end{array}$ & $\begin{array}{c}0.101 \\
(0.104)\end{array}$ & $\begin{array}{c}0.080 \\
(0.083)\end{array}$ & $\begin{array}{c}0.059 \\
(0.063)\end{array}$ & \begin{tabular}{|c|}
0.042 \\
$(0.046)$ \\
\end{tabular} \\
\hline Weight loss (FV2) & $\begin{array}{c}0.000 \\
(0.000) \\
\end{array}$ & $\begin{array}{c}0.000 \\
(0.000) \\
\end{array}$ & $\begin{array}{c}0.000 \\
(0.000)\end{array}$ & $\begin{array}{c}0.000 \\
(0.000)\end{array}$ & $\begin{array}{c}0.001 \\
(0.001) \\
\end{array}$ & $\begin{array}{c}0.001 \\
(0.002) \\
\end{array}$ & $\begin{array}{c}0.002 \\
(0.003) \\
\end{array}$ & \begin{tabular}{|c|}
0.004 \\
$(0.004)$ \\
\end{tabular} \\
\hline CTE fitting parameter $\mathrm{C} 1$ & $\begin{array}{c}0.005 \\
(0.006)\end{array}$ & $\begin{array}{c}0.012 \\
(0.014)\end{array}$ & $\begin{array}{c}0.021 \\
(0.023)\end{array}$ & $\begin{array}{c}0.030 \\
(0.032)\end{array}$ & $\begin{array}{c}0.046 \\
(0.049)\end{array}$ & $\begin{array}{c}0.063 \\
(0.069)\end{array}$ & $\begin{array}{c}0.089 \\
(0.102)\end{array}$ & $\begin{array}{c}0.124 \\
(0.143)\end{array}$ \\
\hline CTE fitting parameter $\mathrm{C} 2$ & $\begin{array}{c}0.355 \\
(0.412)\end{array}$ & $\begin{array}{c}0.344 \\
(0.379)\end{array}$ & $\begin{array}{c}0.342 \\
(0.374)\end{array}$ & $\begin{array}{c}0.351 \\
(0.385)\end{array}$ & $\begin{array}{c}0.368 \\
(0.404)\end{array}$ & $\begin{array}{c}0.382 \\
(0.427)\end{array}$ & $\begin{array}{c}0.388 \\
(0.440)\end{array}$ & $\begin{array}{c}0.394 \\
(0.448) \\
\end{array}$ \\
\hline Virgin Young's modulus (with grain) & $\begin{array}{c}0.026 \\
(0.033)\end{array}$ & $\begin{array}{c}0.021 \\
(0.024)\end{array}$ & $\begin{array}{c}0.016 \\
(0.019)\end{array}$ & $\begin{array}{c}0.014 \\
(0.016)\end{array}$ & $\begin{array}{c}0.011 \\
(0.013)\end{array}$ & $\begin{array}{c}0.009 \\
(0.010)\end{array}$ & $\begin{array}{c}0.007 \\
(0.008)\end{array}$ & \begin{tabular}{|c|}
0.004 \\
$(0.005)$ \\
\end{tabular} \\
\hline Young's modulus weight loss fitting constant $F_{i}$ & $\begin{array}{c}0.072 \\
(0.135) \\
\end{array}$ & $\begin{array}{c}0.098 \\
(0.156) \\
\end{array}$ & $\begin{array}{c}0.117 \\
(0.180)\end{array}$ & $\begin{array}{c}0.131 \\
(0.191)\end{array}$ & $\begin{array}{c}0.137 \\
(0.191)\end{array}$ & $\begin{array}{c}0.133 \\
(0.188)\end{array}$ & $\begin{array}{c}0.124 \\
(0.184)\end{array}$ & \begin{tabular}{|c|}
0.102 \\
$(0.171)$ \\
\end{tabular} \\
\hline Young's modulus weight loss fitting constant $k_{i}$ & $\begin{array}{c}0.207 \\
(0.309) \\
\end{array}$ & $\begin{array}{c}0.243 \\
(0.326)\end{array}$ & $\begin{array}{c}0.263 \\
(0.340)\end{array}$ & $\begin{array}{c}0.265 \\
(0.338)\end{array}$ & $\begin{array}{c}0.250 \\
(0.319)\end{array}$ & $\begin{array}{c}0.229 \\
(0.299)\end{array}$ & $\begin{array}{c}0.198 \\
(0.273)\end{array}$ & $\begin{array}{c}0.159 \\
(0.242) \\
\end{array}$ \\
\hline Secondary creep coefficient & $\begin{array}{c}0.011 \\
(0.015)\end{array}$ & $\begin{array}{c}0.006 \\
(0.007)\end{array}$ & $\begin{array}{c}0.002 \\
(0.002)\end{array}$ & $\begin{array}{c}0.000 \\
(0.000)\end{array}$ & $\begin{array}{c}0.000 \\
(0.000)\end{array}$ & $\begin{array}{c}0.000 \\
(0.000)\end{array}$ & $\begin{array}{c}0.000 \\
(0.000)\end{array}$ & $\begin{array}{c}0.002 \\
(0.005)\end{array}$ \\
\hline Secondary creep_Young's modulus weight loss fitting constant $F_{i}$ & $\begin{array}{c}0.011 \\
(0.014)\end{array}$ & $\begin{array}{c}0.005 \\
(0.006)\end{array}$ & $\begin{array}{c}0.000 \\
(0.000)\end{array}$ & $\begin{array}{c}0.000 \\
(0.000)\end{array}$ & $\begin{array}{c}0.001 \\
(0.002)\end{array}$ & $\begin{array}{c}0.005 \\
(0.006)\end{array}$ & $\begin{array}{c}0.012 \\
(0.017)\end{array}$ & $\begin{array}{c}0.016 \\
(0.031)\end{array}$ \\
\hline Secondary creep_Young's modulus weight loss fitting constant $k_{i}$ & $\begin{array}{c}0.013 \\
(0.018)\end{array}$ & $\begin{array}{c}0.005 \\
(0.006)\end{array}$ & $\begin{array}{c}0.001 \\
(0.001)\end{array}$ & $\begin{array}{c}0.000 \\
(0.000)\end{array}$ & $\begin{array}{c}0.002 \\
(0.002)\end{array}$ & $\begin{array}{c}0.007 \\
(0.008)\end{array}$ & $\begin{array}{c}0.014 \\
(0.017)\end{array}$ & $\begin{array}{c}0.022 \\
(0.035)\end{array}$ \\
\hline Secondary creep_Unirradiated static to dynamic Young's modulus ratio & \begin{tabular}{|c|}
0.018 \\
$(0.022)$ \\
\end{tabular} & $\begin{array}{c}0.007 \\
(0.008) \\
\end{array}$ & $\begin{array}{c}0.002 \\
(0.002)\end{array}$ & $\begin{array}{c}0.000 \\
(0.000) \\
\end{array}$ & $\begin{array}{c}0.000 \\
(0.000)\end{array}$ & $\begin{array}{c}0.000 \\
(0.000)\end{array}$ & $\begin{array}{c}0.001 \\
(0.002)\end{array}$ & \begin{tabular}{|c|}
0.002 \\
$(0.004)$ \\
\end{tabular} \\
\hline Sum of main effects & 0.87 & 0.904 & 0.909 & 0.912 & 0.917 & 0.91 & 0.895 & 0.87 \\
\hline Total Variance & 15.33 & 39.4 & 70.1 & 101.5 & 131.1 & 159.8 & 179.9 & 191.6 \\
\hline
\end{tabular}


Figure 1 (a) Simplified representation of a Hinkley Point B graphite moderator brick (b) Details of the brick features (c) Finite element mesh of an octant of a brick.

Figure 2: Examples of field variables supplied as loading conditions a) dose; b) temperature; c) weight loss.

Figure 3: Plan view of the moderator brick octant showing the comparison locations: LB, LMNB, and LMFB denote the bore and near and far side of the methane hole respectively (all points aligned with the loose keyway). RB, RMNB and RMFB denote the bore and near and far side of the methane hole respectively (all points aligned with the interstitial keyway).

Figure 4: Comparison of stress over strength for baseline model values at 6 locations throughout the height of the brick: LB, LMNB, and LMFB denote the bore and near and far side of the methane hole respectively (all points aligned with the loose keyway). RB, RMNB and RMFB denote the bore and near and far side of the methane hole respectively (all points aligned with the interstitial keyway).

Figure 5: Comparison of maximum in-plane principal stresses (MIPPS) at the loose and interstitial keyway for baseline parameter values.

Figure 6: Profiles of stress to strength ratio for the $100 \mathrm{FE}$ model runs.Profiles for power and shutdown conditions are distinguished between.

Figure 7: Results from cross validation output at $10 \mathrm{fpy}$. Top panels show errors against predictions; bottom panels show outputs against predictions.

Figure 8: Main effect plots for the six dominant parameters in the FE model. Plots show the average effect of a parameter on the stress to strength ratio for results at power (blue) and at shutdown (black).

Figure 9: Maximum in-plane principal stress at power and shutdown conditions, for each of the 200 model runs.

Figure 10: Results from cross validation output at 26 to $40 \mathrm{fpy}$. Top panels show errors against predictions; bottom panels show outputs against predictions.

Figure 11: Main effect plots for the two field variables and the six dominent material property parameters at the at-power. Plots show the average effect of a parameter on MIPPS for results at $20 \mathrm{fpy}$ (black), $30 \mathrm{fpy}$ (blue) and $40 \mathrm{fpy}$ (red).

Figure 12: Main effect plots for the two field variables and the six dominent material property parameters at the at-shutdown. Plots show the average effect of a parameter on MIPPS for results at 20 fpy (black), 30 fpy (blue) and 40 fpy (red). 


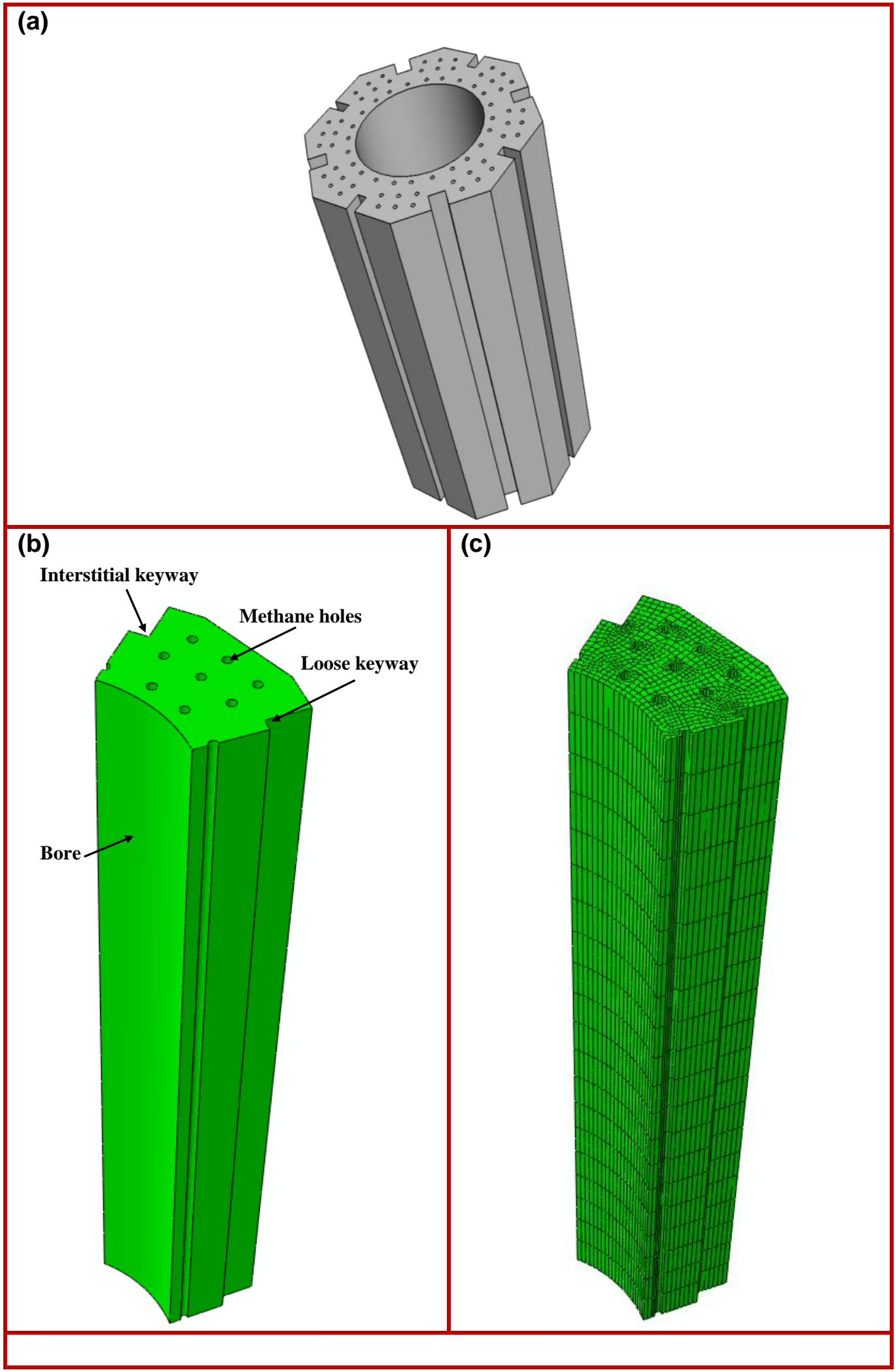


(a)

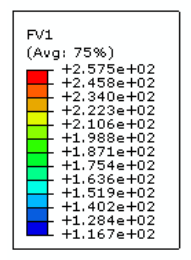

" (b)

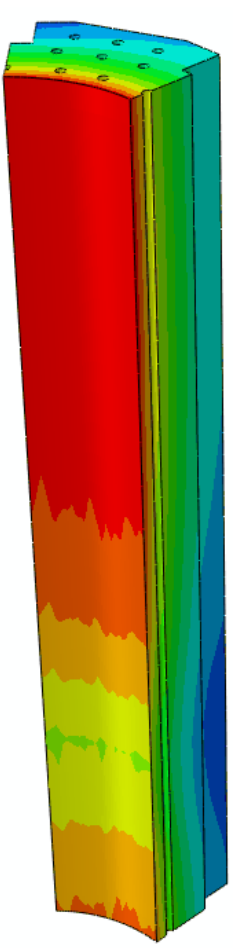

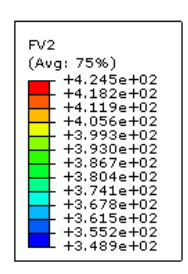

" (c)

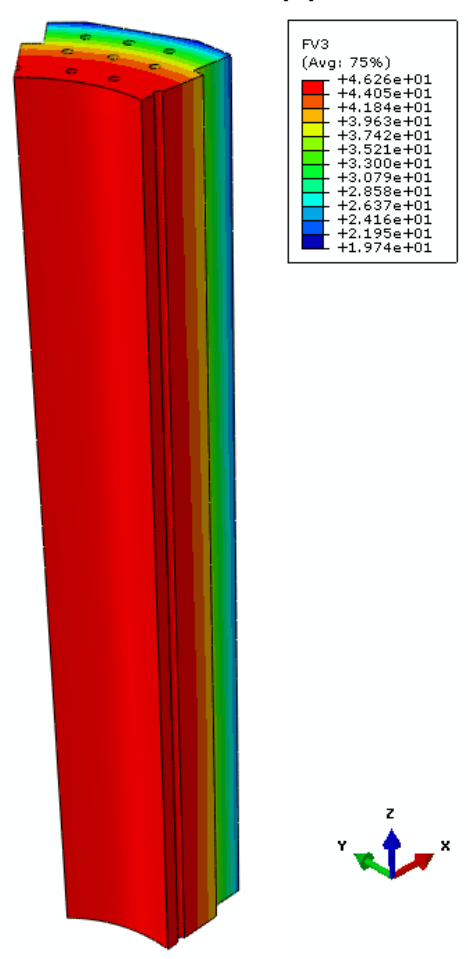

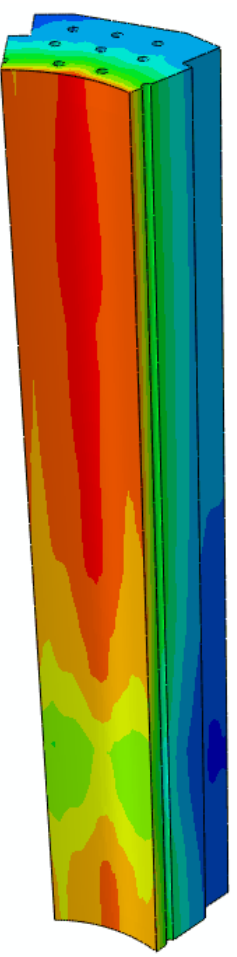




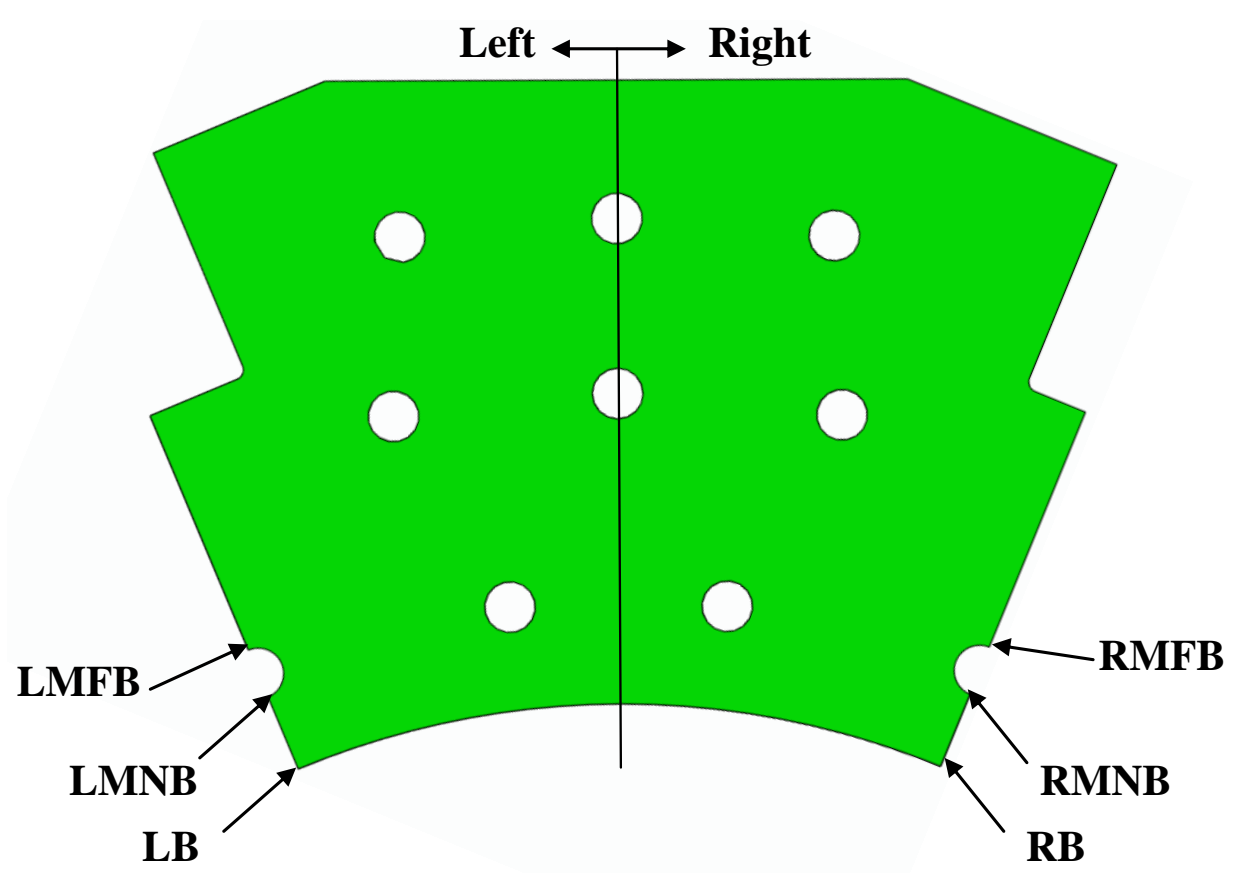




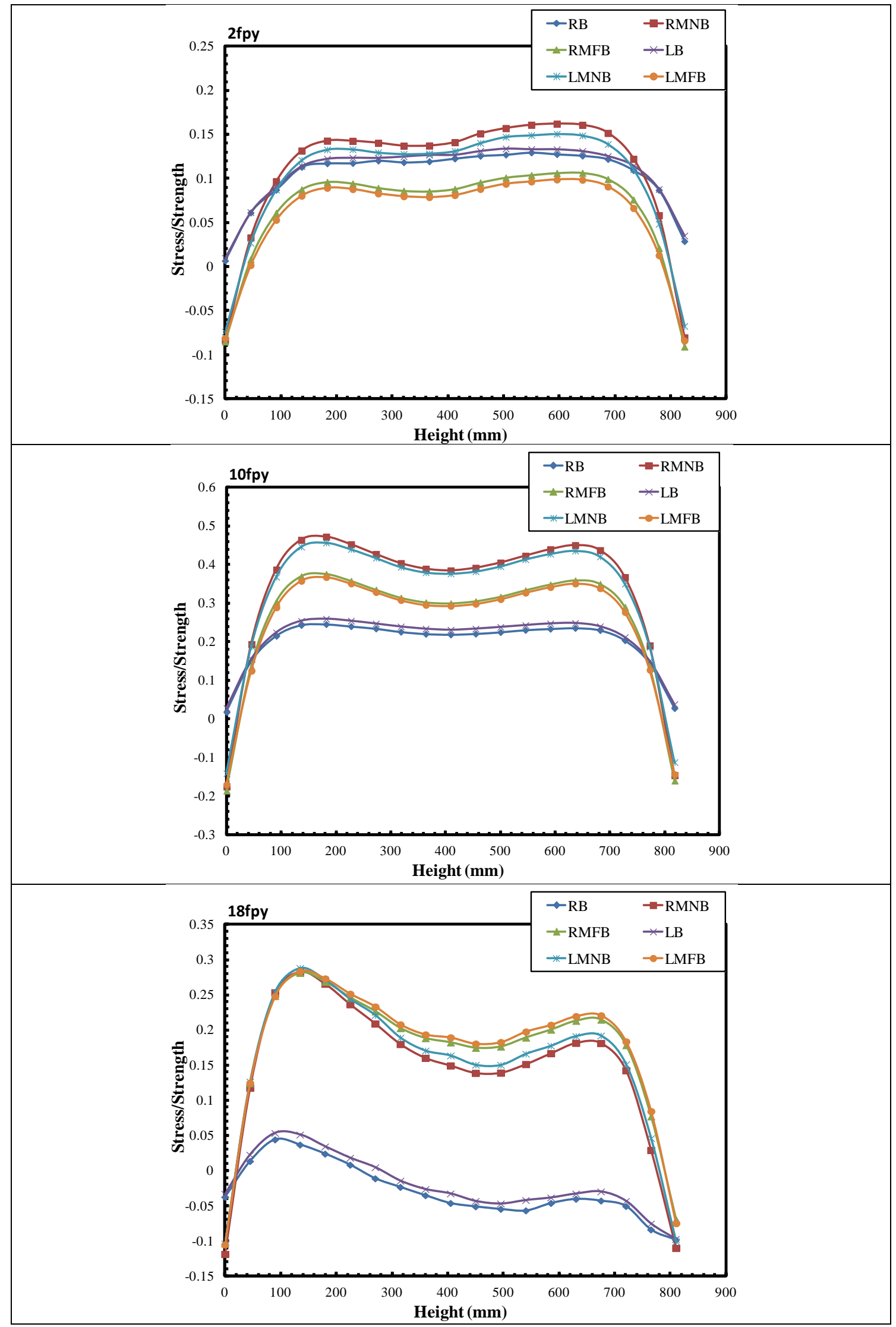




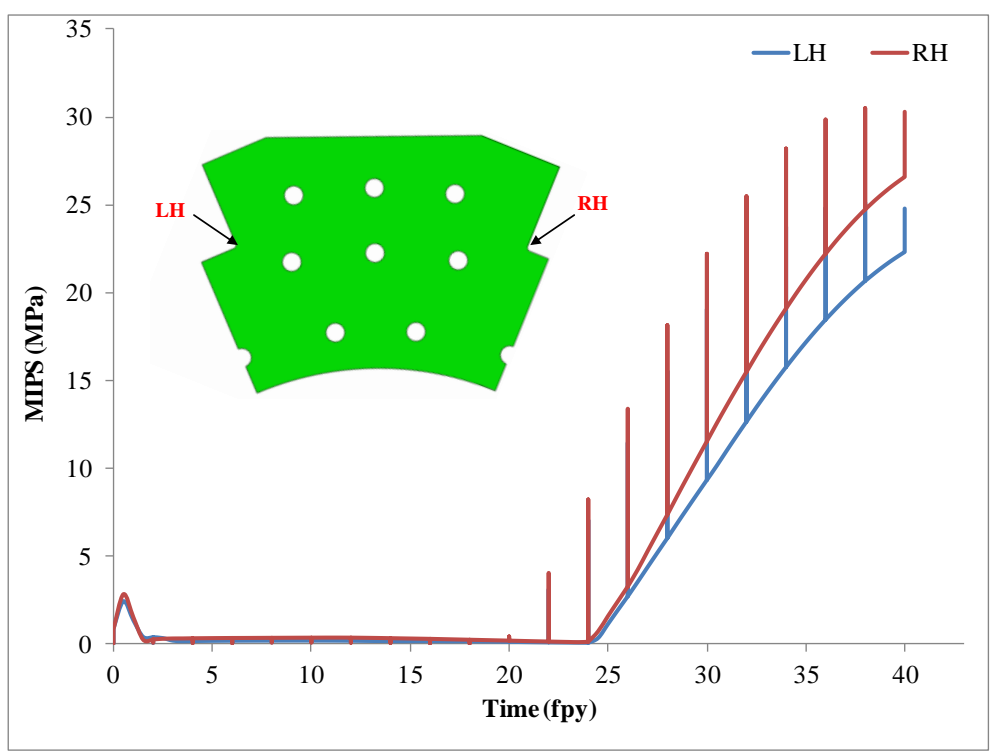




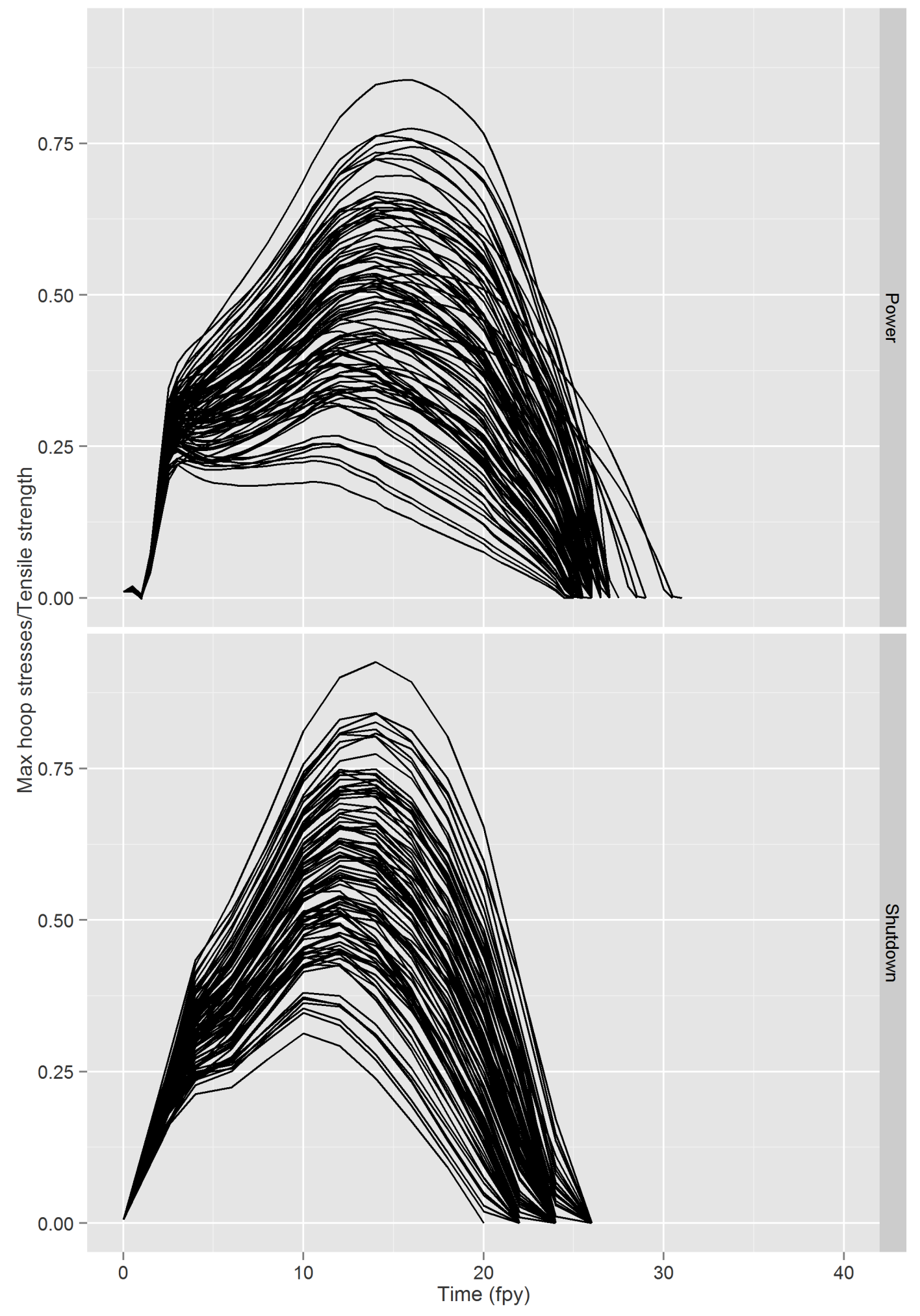




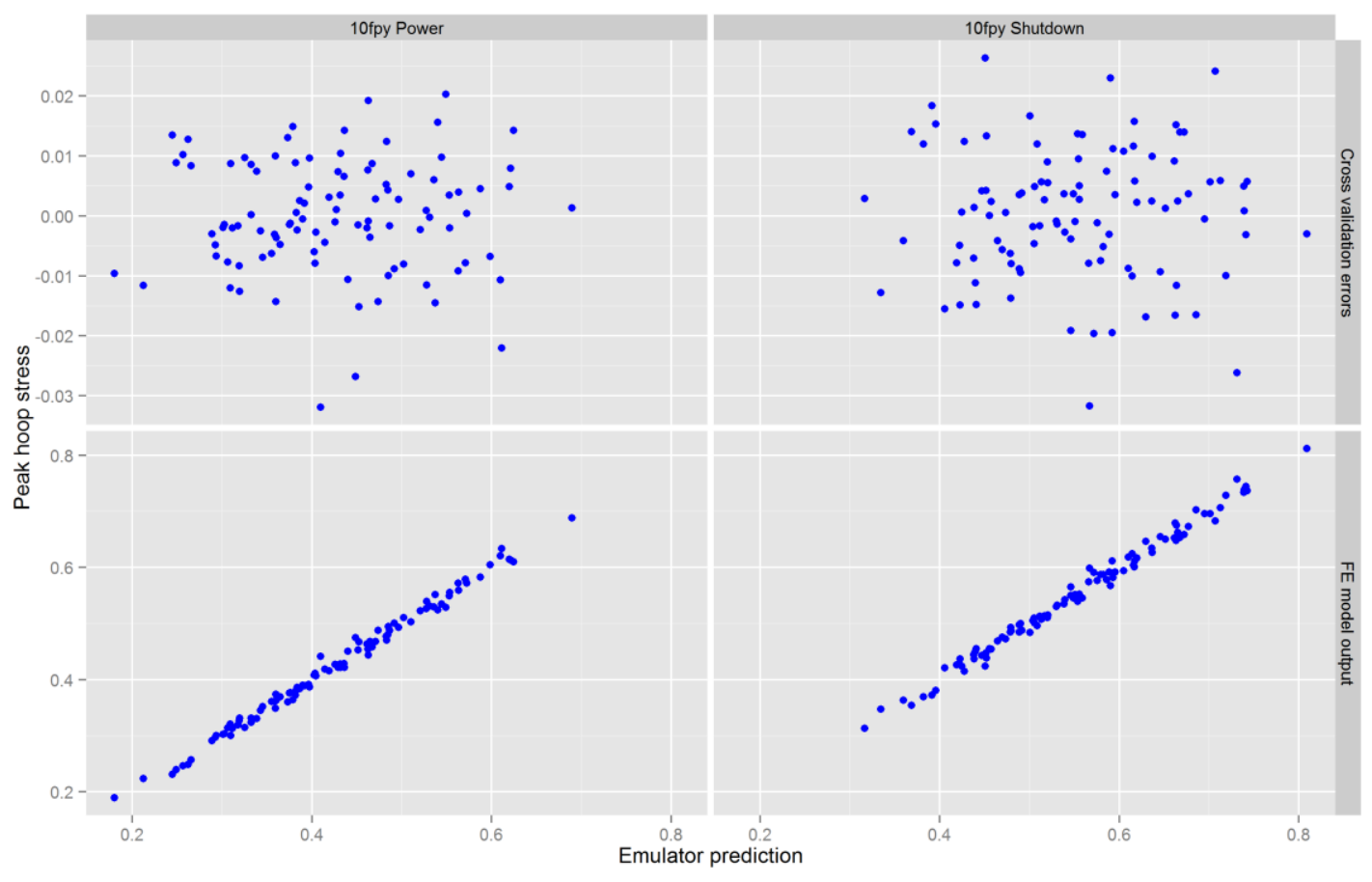



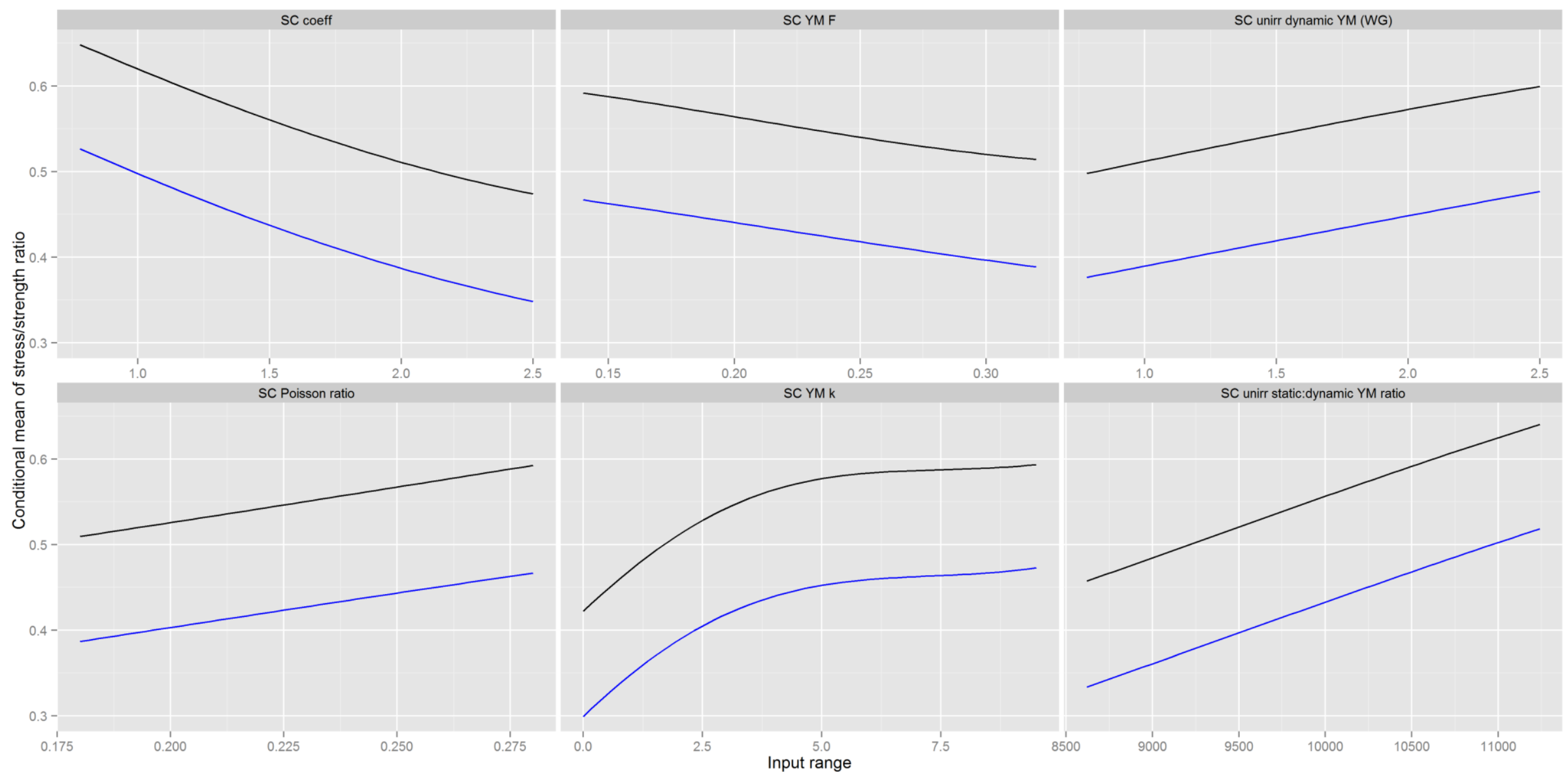


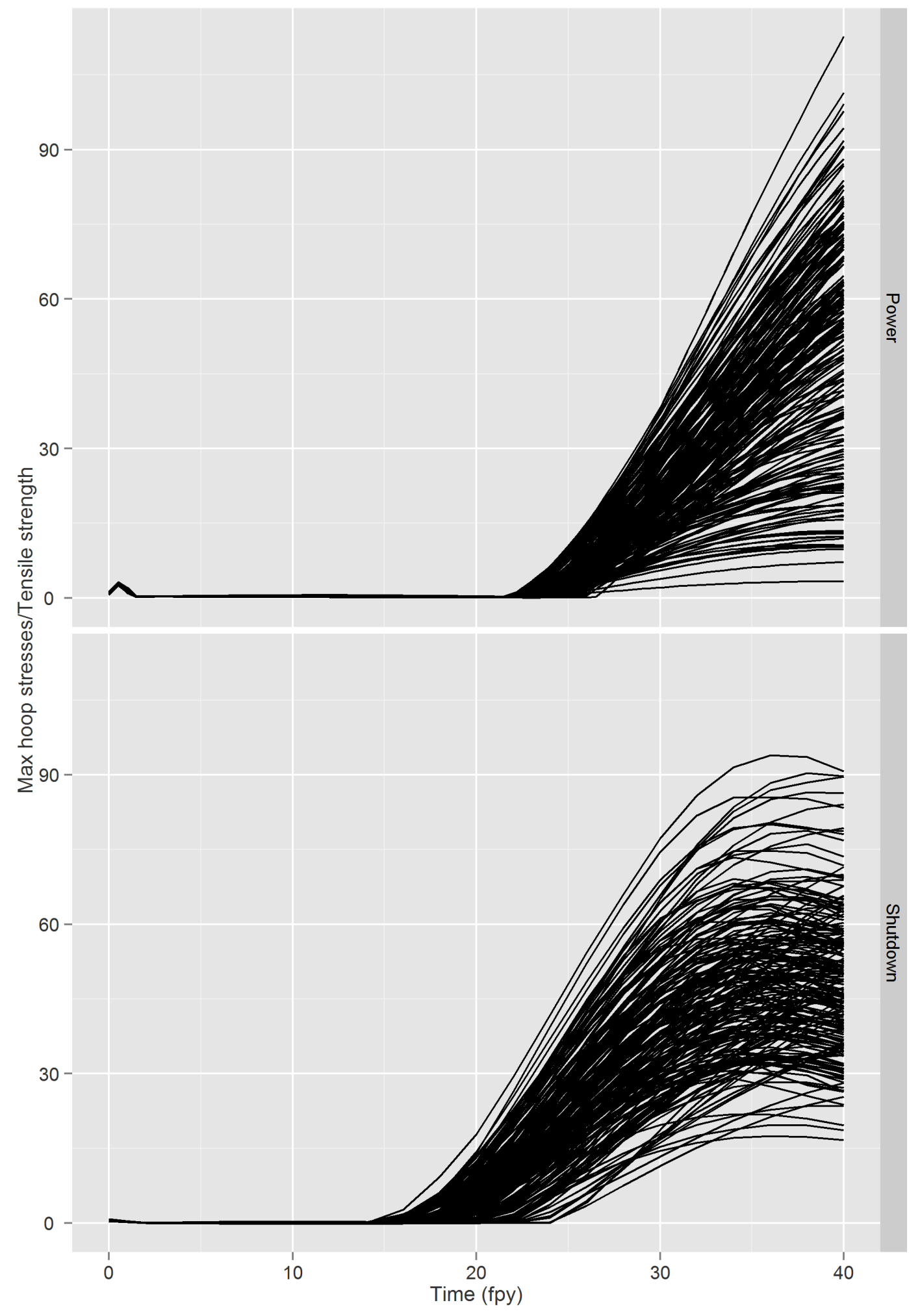



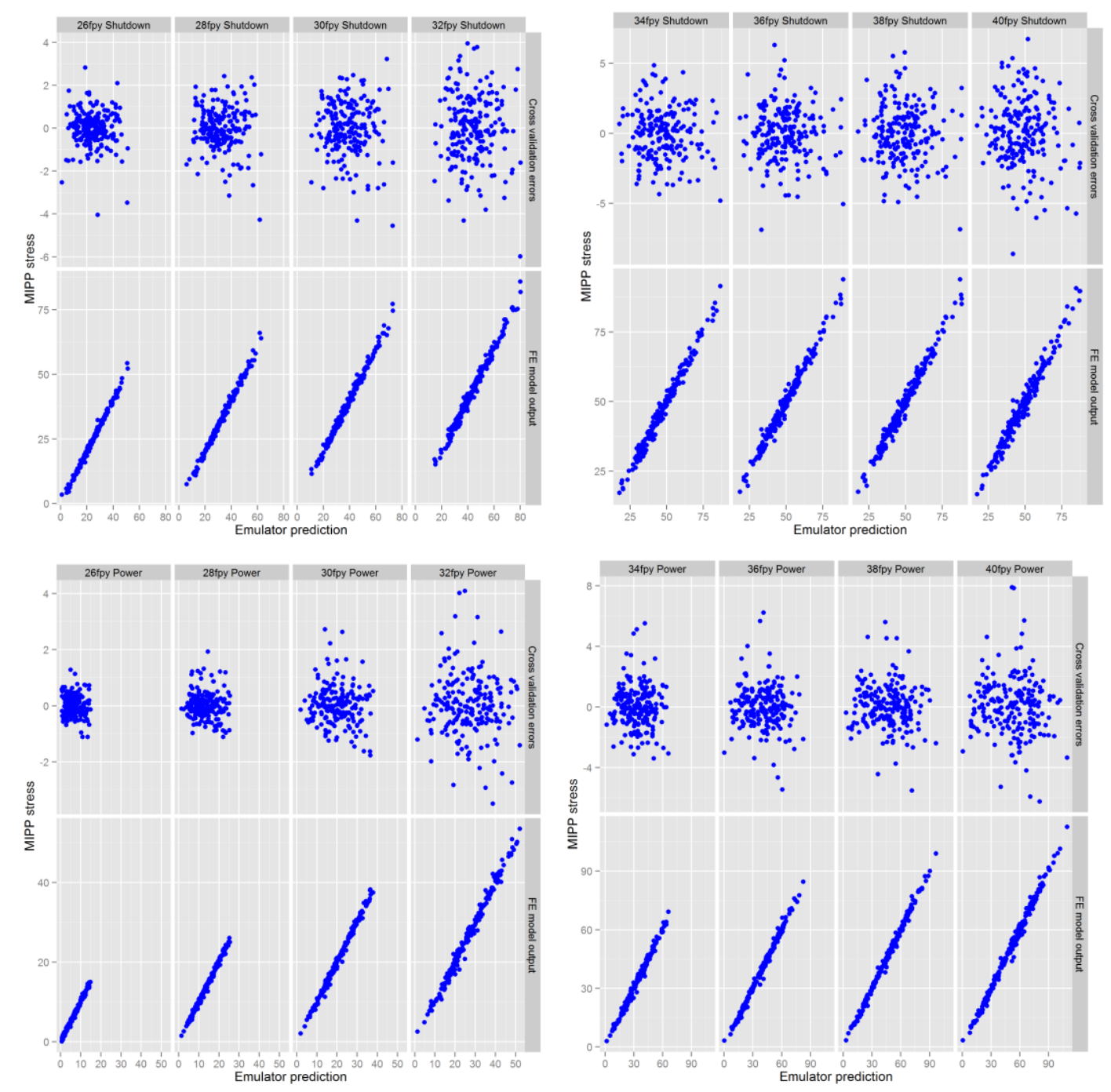


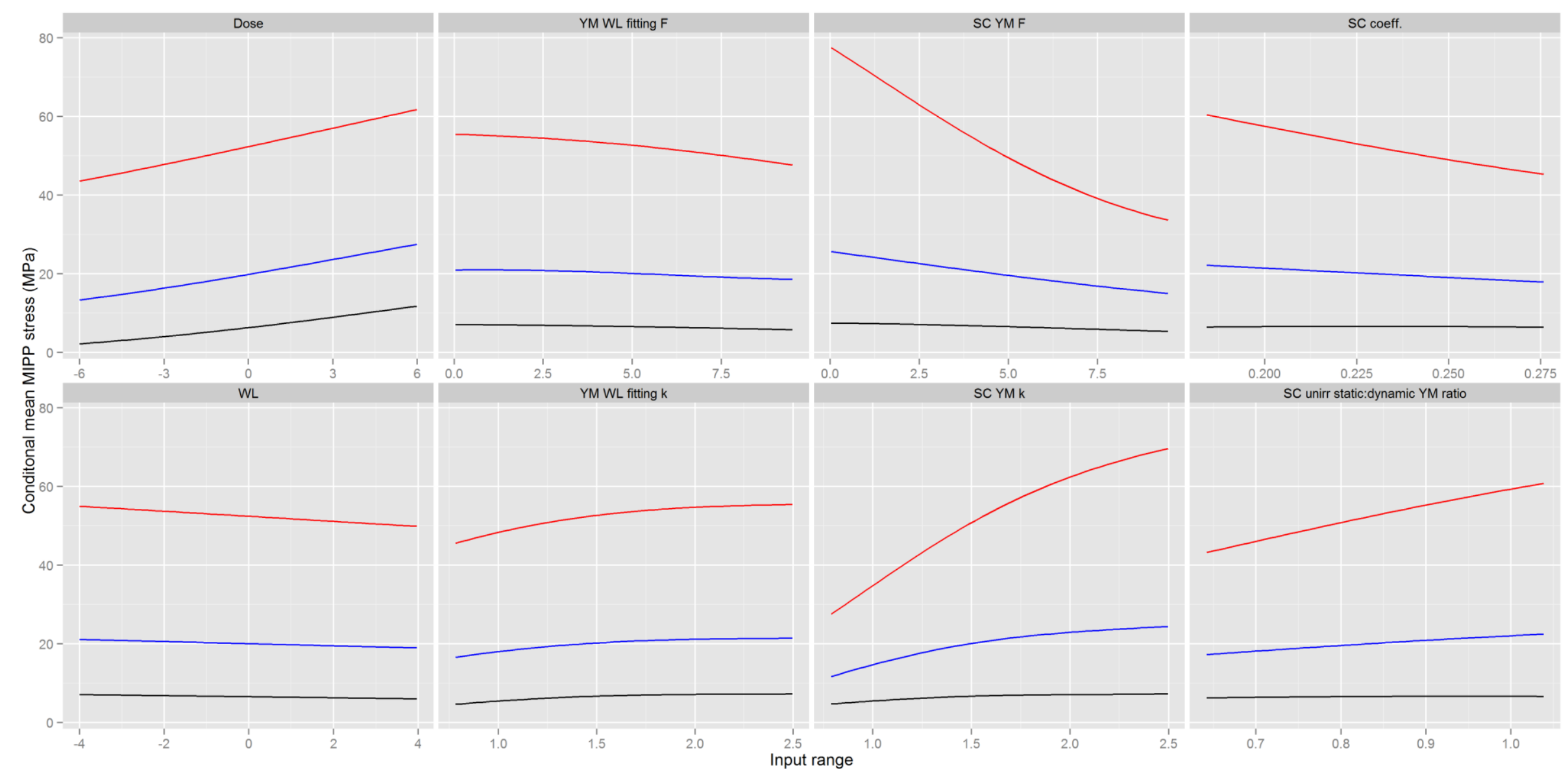




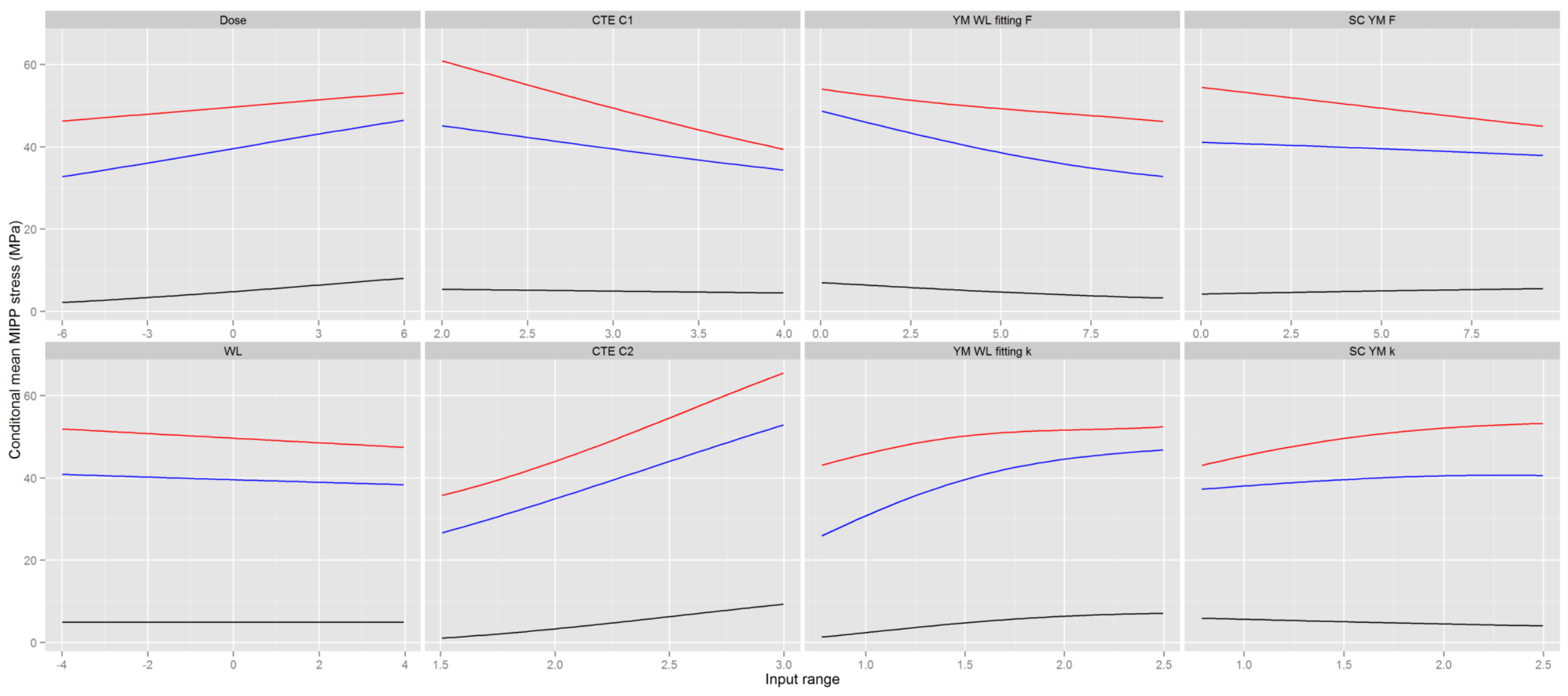

